CARLOS BÖRDER

\title{
ANÁLISE DO COEFICIENTE DE ATRITO NO ENSAIO DO ANEL PARA O FORJAMENTO A QUENTE
}

Trabalho de curso do Mestrado Profissionalizante em Engenharia Automotiva da Escola Politécnica da Universidade de São Paulo. 
CARLOS BÖRDER

\section{ANÁLISE DO COEFICIENTE DE ATRITO NO ENSAIO DO ANEL PARA O FORJAMENTO A QUENTE}

Trabalho de curso do Mestrado Profissionalizante em Engenharia Automotiva da Escola Politécnica da Universidade de São Paulo.

Orientador: Prof. Dr. Amilton Sinatora

São Paulo

2005 


\section{DEDICATÓRIA}

À minha esposa Lygia e às minhas filhas Priscila e Stephanie dedico este trabalho, que corresponde a muitas horas de sacrifício da vida familiar, mas que também muito nos ensinou, principalmente na cooperação e na participação da família para se obter um objetivo comum.

"In Memorian"

Aos meus pais Rudolf e Antonia responsáveis pela minha formação pessoal e profissional. 


\section{AGRADECIMENTOS}

À empresa ThyssenKrupp Metalúrgica Campo Limpo pela oportunidade, suporte e apoio neste trabalho.

Aos colegas da empresa e profissionais que participaram nas discussões e análises em especial:

Eng. Leopoldo Rodolfo Algueiro Koller

Eng. Roberto Cláudio Miranda.

Eng. Rodrigo Spinola Ribeiro de Oliveira.

Ao meu orientador Prof. Dr. Amilton Sinatora por todo apoio, suporte técnico e científico.

Aos colegas do Laboratório de Fenômenos de Superfície do Departamento de Engenharia Mecânica da EPUSP pela orientação e apoio. 


\section{RESUMO}

O presente trabalho, apresenta resultados da investigação experimental e da análise computacional acerca do método de ensaio de anéis de aço para obtenção do valor do coeficiente de atrito, existente na região de contato entre as matrizes e os corpos de prova.

Buscando atingir os objetivos, foi feito um planejamento do experimento, através do programa MINITAB (2000), levando-se em consideração as variáveis do processo para forjamento a quente de peças para indústria automotiva, os experimentos foram realizados nos laboratórios da Universidade Federal do Rio Grande do Sul (UFRGS).

A simulação do ensaio de anel permitiu uma boa estimativa da redução de diâmetros dos mesmos, bem como, do fluxo de material no interior dos anéis e da superfície neutra.

A análise estatística dos resultados mostrou que a variável mais importante a afetar o coeficiente de atrito foi a temperatura, seguindo-se do tipo de revestimento das ferramentas, velocidade e material.

Para um estudo mais pormenorizado do efeito do material a ser forjado, do recobrimento das ferramentas e da rugosidade das mesmas no coeficiente de atrito será necessário um maior número de repetições dos experimentos. 


\begin{abstract}
The present work introduces the result of the experimental investigation and computing analyses regarding the method of trial with steel rings as to obtain the value of friction coefficient, which exist in the contact area between the tools and test bodies.
\end{abstract}

Aiming to reach the objectives, a design of experiments was established through the program MINITAB (2000) taking into account the process variables in order to hot forge parts for the automotive industry, being such experiments accomplished at the laboratories of the "Universidade do Rio Grande do Sul (UFRGS)".

The simulation trial of the ring allowed for good estimate of its diameters reduction as well as internal material flow in the rings and in the neutral surface.

The static analyses of the results demonstrated that the most important isolated variable to affect the friction coefficient was temperature, followed by the type of tools covering, velocity and material.

However a bigger number of experiments repetitions will be necessary in order to reach a more detailed study about the effect of the material to be forged, of tools covering and roughness in the friction coefficient as well. 


\section{LISTA DE FIGURAS}

Figura 1: Martelete movido a água, obtido de Forging Handbook (1985) 3

Figura 2: Martelo de Nasmith, obtido de Forging Handbook (1985) 3

Figura 3: Peças da cultura "Sicán” encontradas em escavações no Peru em 1992, conforme Vetter (1996) .5

Figura 4: Peças forjadas para primeiros veículos obtido de Forging Handbook (1985)

Figura 5: Tensão tangencial em função da pressão normal. Os valores do coeficiente de atrito $(\mu)$, bem como valores do fator de cisalhamento (m), obtido de Schey (1984)

Figura 6: Variação do coeficiente de atrito ( $\mu$ ) com a pressão normal (p), gráfico, obtido de Schey (1984)

Figura 7: Indicação da superfície neutra no forjamento do anel.

Figura 8: Gráfico com as variações de coeficiente de atrito ( $\mu$ ) com a temperatura para o cobre e para o aço carbono, obtido de Male e Cockroft (1964)

Figura 9: Gráfico com a influência do teor zinco em ligas de cobre, no coeficiente de atrito $(\mu)$, obtido de Male (1966)

Figura 10: Gráfico com fator de cisalhamento de atrito $m$, de vários tipos de aço em uma curva de calibração analítica, obtido de Wang e Lenard (1992) 
Figura 11: Gráfico comparativo com valores teóricos (linha cheia) do coeficiente de atrito $(\mu)$ ou do fator de cisalhamento de atrito $(m)$, no gráfico representado por $(\alpha)$ onde $\alpha p=\mu k$, com valores experimentais (linha tracejada) para os materiais: a) aço sem lubrificante, b) cobre sem lubrificante, c) aço sem lubrificante e matrizes polidas, d) cobre lubrificado com grafite, e) latão lubrificado com lanolina, f) alumínio lubrificado com parafina obtido de Hawkyard e Johnson (1967)

Figura 12: Geometria proposta para calibração do modelo de atrito em condições de baixos níveis de pressão normal adaptado de Petersen, Martins e BAY (1997)

Figura 13: Ensaio do anel na forma convencional com as curvas de calibração obtidas em simulação com os modelos de atrito conforme equação 4 (linha cheia) e equação 8 (linha tracejada), conforme Petersen, Martins e Bay (1998)

Figura 14: Ensaio do anel com forma de acordo a figura 12 e curva de calibração obtida com a simulação adotando-se o modelo de atrito conforme equação 8, conforme Petersen, Martins e BAY (1998).

Figura 15: Ensaio do anel com forma de acordo com a figura 12 e curva de calibração obtida com a simulação adotando-se o modelo de atrito conforme equação 4 conforme Petersen, Martins e BAY (1998)

Figura 16: Conjunto para ensaio do anel, no LdTM da UFRGS. Forno, prensa e instrumentação. 
Figura 17: Matriz montada na prensa do LdTM da UFRGS para o ensaio de anéis com sistema de aquecimento.

Figura 18: Matrizes usadas no ensaio de anéis,com marcas da região de apoio dos anéis.

Figura 19: Amostras de anéis ensaiadas no LdTM da UFRG prensados. 38

Figura 20: Curva de calibração gerada com diâmetros obtidos pelo programa de simulação FORGE 3 (2004), para o material DIN 38MnSiVS 5 . 42

Figura 21: Curva de calibração gerada com diâmetros obtidos pelo programa de simulação FORGE 3 (2004), para o material SAE 1548

Figura 22: Vetores velocidade de escoamento de material na simulação do ensaio de compressão do anel, obtido através do programa FORGE 3 (2004), amostra 7

Figura 23: Vetores velocidade de escoamento de material na simulação do ensaio de compressão do anel, obtido através do programa FORGE 3 (2004), amostra 11

Figura 24: Velocidade de escoamento do material na simulação do ensaio de compressão do anel, obtido através do programa FORGE 3 (2004), amostra 7.

Figura 25: Velocidade de escoamento do material na simulação do ensaio de compressão do anel, obtido através do programa FORGE 3 (2004), amostra 11

Figura 26: Perfil de temperatura do anel durante simulação do ensaio de 
compressão do anel, obtido através do programa FORGE 3 (2004), amostra 7 ensaio a $800^{\circ} \mathrm{C}$

Figura 27: Perfil de temperatura do anel durante simulação do ensaio de compressão do anel, obtido através do programa FORGE 3 (2004), amostra 11 ensaio a $1200^{\circ} \mathrm{C}$

Figura 28: Efeito das variáveis do processo de forjamento a quente no coeficiente de atrito, obtido com programa MINITAB (2000)

Figura 29: Gráfico com a influência das variáveis de processo de forjamento a quente no coeficiente de atrito para confiabilidade $95 \%$

Figura 30: Superfície de contato da amostra 26 com a matriz, com ampliação de $4 x$ 60

Figura 31: Superfície de contato da amostra 27 com a matriz,com ampliação de $4 x$ 60

Figura 32: Corte da amostra 17 mostrando fibramento e a superficie neutra. 


\section{LISTA DE TABELAS}

Tabela 1: Composição química dos aços (\% em peso). Análise por espectrometria.

Carbono por combustão

Tabela 2: Combinação das variáveis de processo

Tabela 3: Raio do anel medido pelo processo de simulação para o material DIN $38 \mathrm{MnSiVS}_{5}$

Tabela 4: Raio do anel medido pelo processo de simulação para o material SAE 1548

Tabela 5: Tabela com resultados dos diâmetros e alturas dos anéis obtidos nos experimentos

Tabela 6: Valores dos coeficientes de atrito $(\mu)$ para cada experimento

Tabela 7: Diâmetro interno do anel obtido com a simulação de cada experimento 45

Tabela 8: Comparação dos diâmetros internos obtidos nos ensaios e nas simulações feitas com o programa FORGE 3 (2004) 46

Tabela 9: Tabela com médias e desvios das combinações dos experimentos 55

Tabela 10: Continuação da tabela 9 com médias e desvios dos experimentos 56 


\title{
LISTA DE SÍMBOLOS
}

\author{
$\mathrm{d}_{0} \quad$ Diâmetro inicial do anel antes da compressão \\ d Diâmetro final do anel após compressão \\ $f \quad$ Fator de cisalhamento no modelo geral de Wanheim-Bay \\ F $\quad$ Força de atrito \\ h Altura, espessura \\ K Constante \\ $m \quad$ Fator de cisalhamento de atrito \\ $p \quad$ Pressão normal na interface \\ $P \quad$ Força normal \\ $R a \quad$ Rugosidade aparente \\ Rt Rugosidade total \\ T Temperatura \\ V Velocidade \\ $\alpha \quad$ Relação de áreas \\ $\alpha_{f} \quad$ Coeficiente de atrito para modelo "viscoplastic" FORGE 3 (2004) \\ $\dot{\gamma} \quad$ Taxa da tensão de cisalhamento \\ $\Delta \mathrm{D} \quad$ Variação percentual de diâmetros \\ $\eta \quad$ Viscosidade
}


$\mu \quad$ Coeficiente de atrito

$\sigma \quad$ Tensão normal

of Tensão de compressão

$\sigma_{s} \quad$ Tensão de cisalhamento para o modelo de Avitzur (1995)

$\tau i \quad$ Tensão de cisalhamento de atrito na interface 


\section{SUMÁRIO}

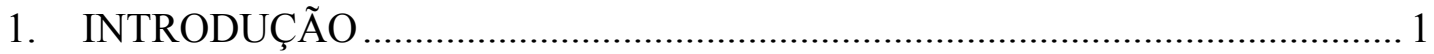

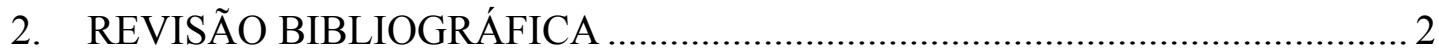

2.1 A História do Forjamento ................................................................ 2

2.2 Visão Futura do Forjamento................................................................ 7

2.3 O Forjamento na Indústria Automotiva ................................................ 9

2.4 Variáveis do Processo de Forjamento ...................................................... 10

2.5 Atrito na Conformação Plástica ........................................................... 12

2.6 Métodos Experimentais para Determinação do Atrito................................ 19

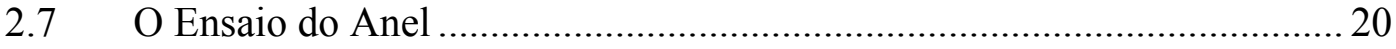

2.7.1 Fatores que Podem Influenciar no Coeficiente de Atrito.......................22

2.7.2 A Abordagem Analítica do Ensaio do Anel..........................................2.25

2.7.3 Novas Visões do Ensaio do Anel ............................................................ 26

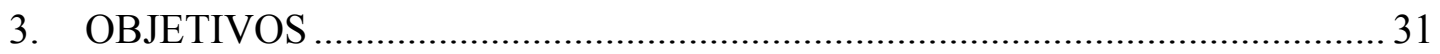

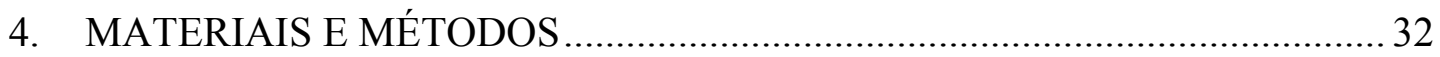

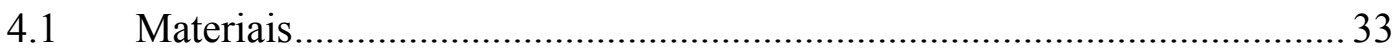

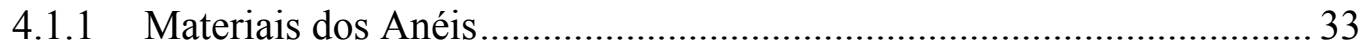

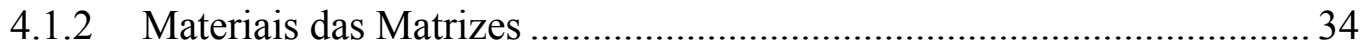

4.1.3 Lubrificante Usado no Experimento ...................................................... 35 


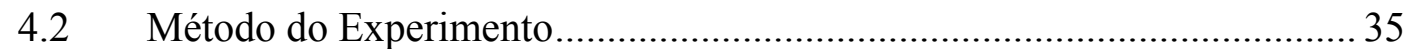

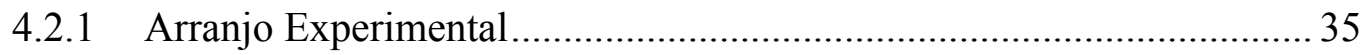

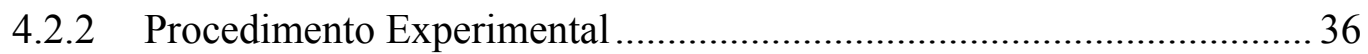

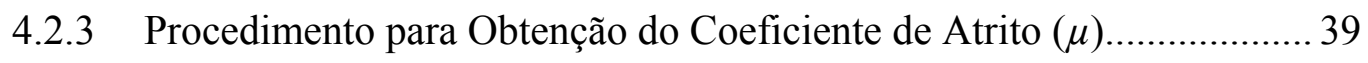

4.2.4 Procedimento para Simulação do Experimento ........................................ 43

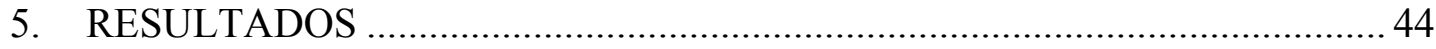

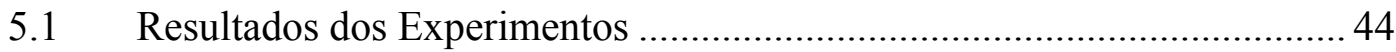

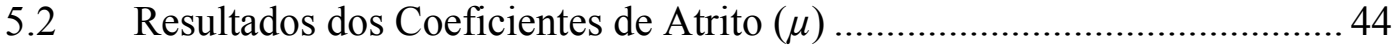

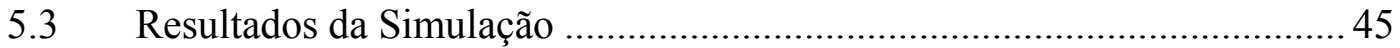

5.4 Comparação de Resultados ..................................................................... 46

5.5 Resultados Gráficos da Simulação ........................................................... 46

5.5.1 Vetores Velocidade de Escoamento de Material .................................. 47

5.5.2 Velocidade de Escoamento do Material............................................. 49

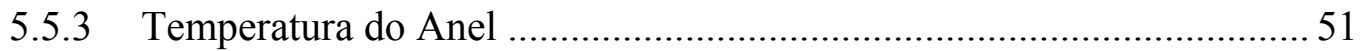

5.6 Resultados Estatísticos dos Experimentos .......................................... 53

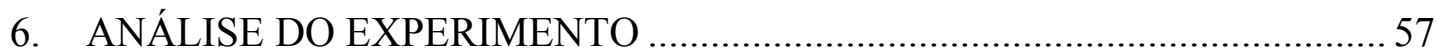

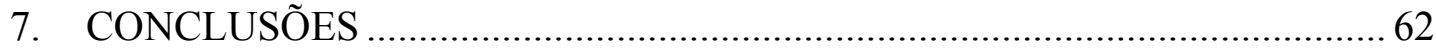

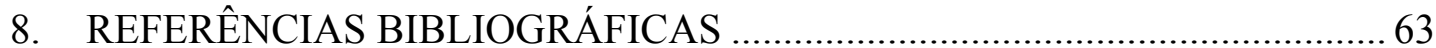




\section{INTRODUÇÃO}

O processo de forjamento do metal a quente traz uma melhoria significativa nas propriedades mecânicas do metal em relação ao fundido.

Buscar o entendimento do efeito das variáveis de forjamento no produto final ou no processo produtivo é um ponto muito importante para o sucesso e o avanço tecnológico necessário de uma forjaria. $\mathrm{O}$ atrito durante o processo de conformação interfere diretamente na vida das matrizes, qualidade do produto e capacidade dos equipamentos empregados no processo.

Em conseqüência, a pesquisa e desenvolvimento objetivam uma redução no peso das peças forjadas sem comprometer a segurança e em muitos casos aumentando significativamente a resistência, a vida útil das peças, precisão, similaridade e economia de energia. 


\section{REVISÃO BIBLIOGRÁFICA}

\subsection{A História do Forjamento}

O forjamento é atualmente uma técnica altamente desenvolvida, porém como foi descrito por Lange e Meyer (1977), é um processo de transformação de metal que encontra suas origens por volta de 4000 a.C., no final da era neolítica. Antes mesmos dos ferreiros, já existiam os ourives e artesãos, que trabalhavam na fabricação de objetos ornamentais ou de troca, feitos em prata ou cobre.

No Egito, as técnicas de forjamento já eram conhecidas na fabricação de peças de ferro meteórico no $4^{\mathrm{o}}$ milênio a.C., entretanto o grande desenvolvimento do forjamento começou com a exploração do ferro proveniente do minério, inicialmente no reino dos Hititas. Em decorrência disso, por volta dos anos 700 a 500 a.C., o ferro substituiu quase completamente o bronze nas armas, nas ferramentas e em outros equipamentos. Logo, aprendeu-se a temperar o ferro como foi transmitido por Homero. Os ferreiros daquela época gozavam de grande prestígio. Os gregos adoravam Hephaistus, na mitologia germânica se conhece Wieland, ambos ferreiros.

Nesta época o que limitava o tamanho das peças forjadas, era a força muscular do ferreiro, as maiores peças forjadas eram as âncoras de navios. Para se obter peças maiores, foi desenvolvido o processo de soldadura pelo forjamento. Neste período, a maior peça forjada conhecida foi a coluna de Delhi, com diâmetro de $400 \mathrm{~mm}$ e altura de 7,25m, sua idade é atribuída entre alguns séculos a.C. até 300 d.C.

O desenvolvimento do processo de forjamento se deve à utilização de máquinas com capacidade de aumentar a força e a energia aplicada ao metal no processo de conformação. 
No período após 1200 d.C., foram usados marteletes acionados por água mostrado na figura 1 .

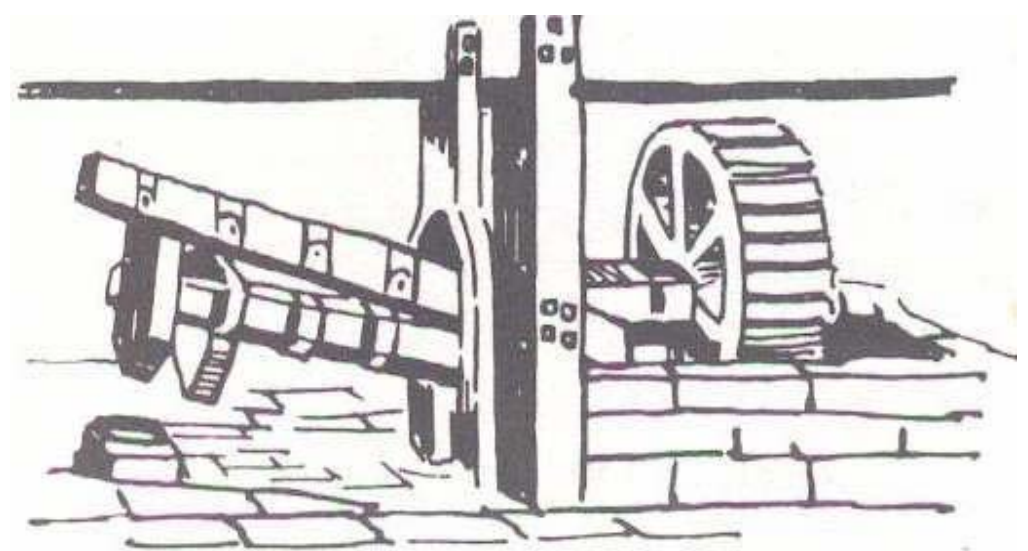

Figura 1: Martelete movido a água, obtido de Forging Handbook (1985)

Neste período, foram forjados equipamentos para lavoura e também armas de fogo, como por exemplo, os tubos ocos para canhões.

O martelo de Nasmith iniciou uma nova era do forjamento em 1839, figura 2.

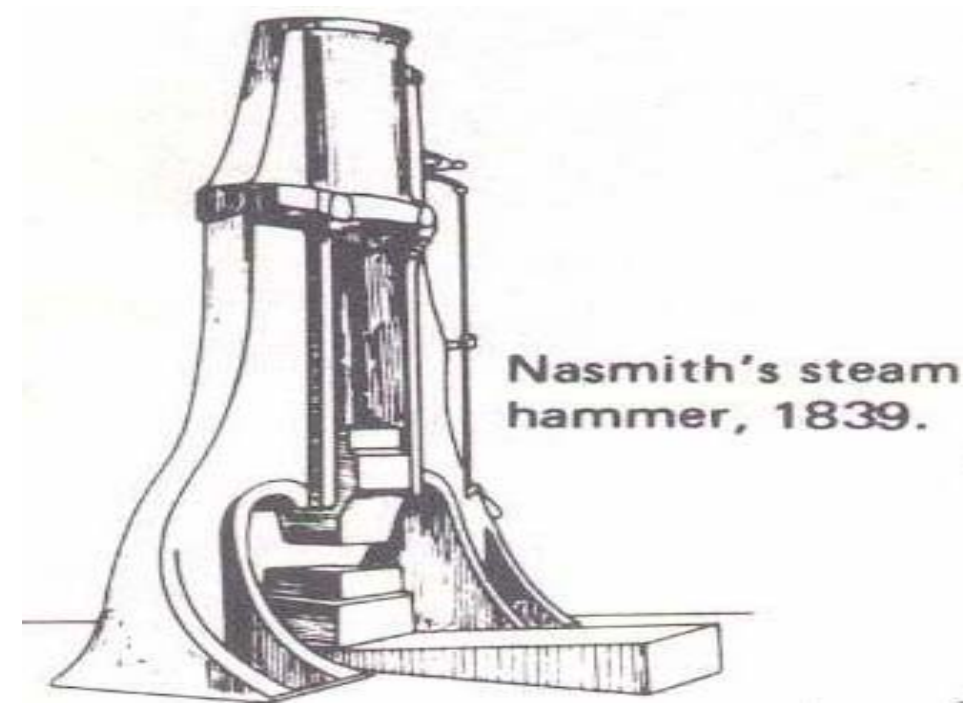

Figura 2: Martelo de Nasmith, obtido de Forging Handbook (1985) 
Em 1860 houve o desenvolvimento de prensas, com a primeira prensa hidráulica de forjamento livre de Haswell.

No campo das ferramentas, os primeiros precursores foram as antigas formas usadas para fabricar peças ornamentais, em chapas de ouro e prata, nas cidades de Mecenas e Creta, em 1600 a.C. A partir de 800 a.C., foram fabricadas moedas de formatos semelhantes e a partir de 600 a.C. foram conhecidas as primeiras ferramentas de bronze.

Em 200 d.C. foi utilizada em Roma uma matriz fechada para cunhagem de moedas com guias quadráticas para o punção superior, evidenciando a noção de centralização das ferramentas.

Já na América do Sul e Central, inúmeras peças forjadas foram encontradas em escavações. Vetter (1996) apresentou um trabalho com ponteiras forjadas, encontradas em 1992 e datadas de 900 a 1100d.C. em uma tumba da cultura "Sicán" (700 a 1375 d.C.) na costa norte do Peru. Elas foram fabricadas em cobre tendo como segundo elemento de liga o arsênico, isso demonstra que naquela época já havia o conhecimento da técnica de forjamento e recozimento do material, estas peças podem ser vistas na figura 3 . 


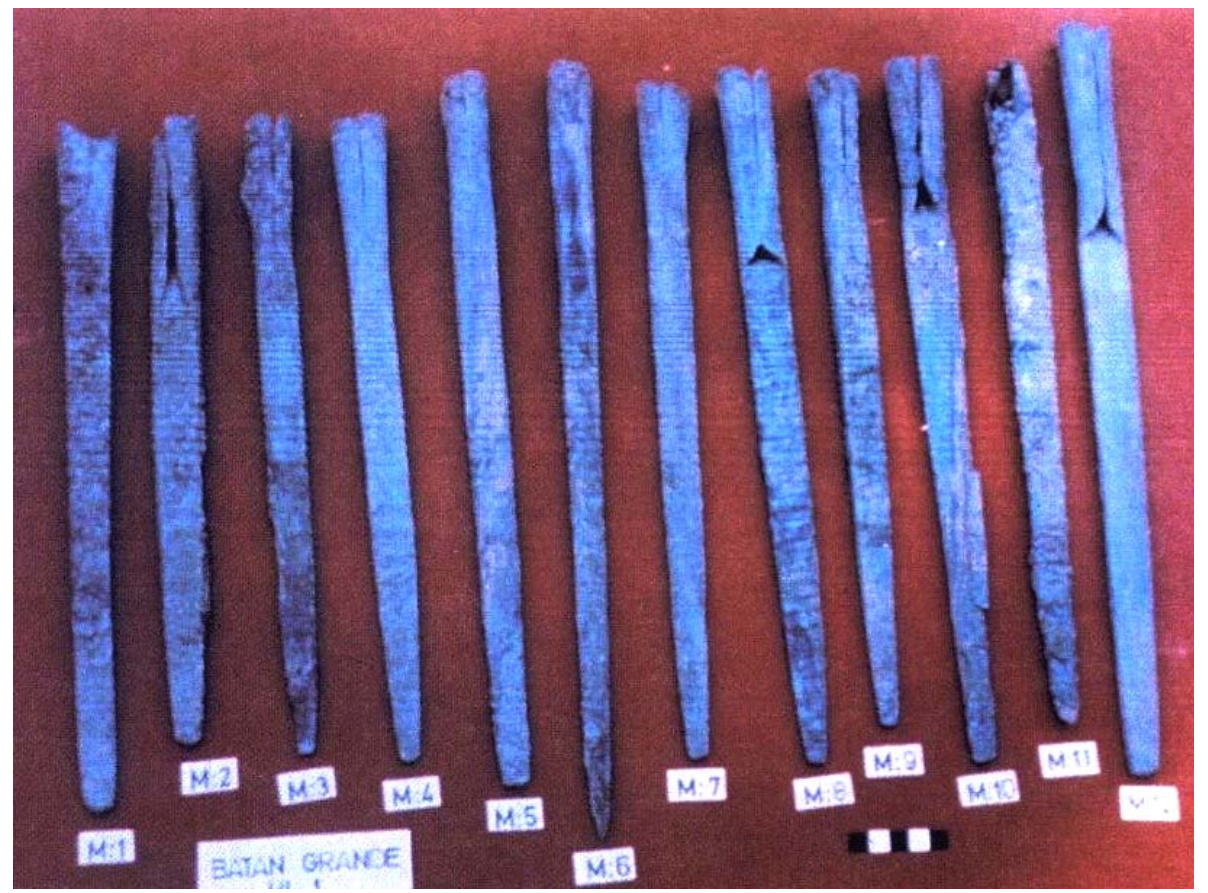

Figura 3: Peças da cultura "Sicán” encontradas em escavações no Peru em 1992, conforme Vetter (1996)

No fim da idade média, foram utilizadas matrizes de rolar para o forjamento de balas de canhão ou para o forjamento de canos de armas.

Todas as técnicas de forjamento envolvendo matrizes e máquinas de conformação com guias das partes móveis, e das próprias matrizes, se juntam essencialmente no decorrer do século XIX, dando-se início às atuais técnicas de forjamento com matrizes.

Este processo de fabricação que forma a base de uma atividade industrial própria teve um forte impulso em seu desenvolvimento, com o início da fabricação de veículos automotivos figura 4. 


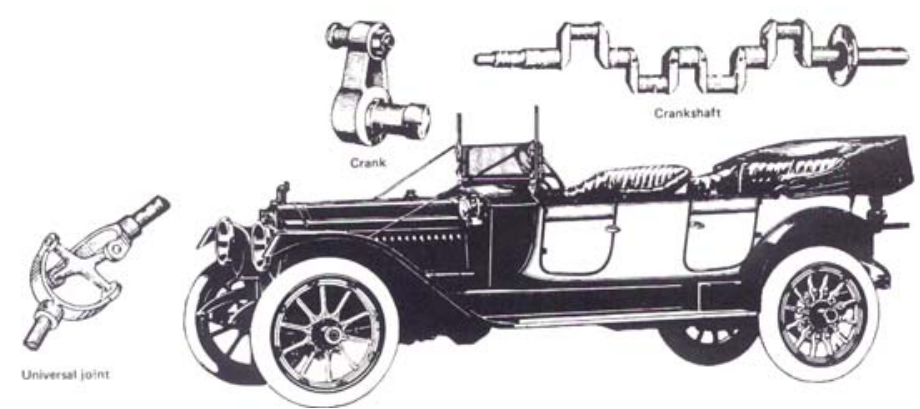

Figura 4: Peças forjadas para primeiros veículos obtido de Forging Handbook (1985)

Posteriormente, também com a indústria aeronáutica houve um grande salto com o emprego de novos materiais e de novos processos de forjamento.

As peças forjadas ficavam cada vez maiores, mais pesadas e mais complexas. Os metais e ligas cada vez mais variados, ao mesmo tempo em que a precisão das peças forjadas em matrizes aumentou.

Este desenvolvimento foi incentivado em alguns países com as primeiras normas de tolerância de fornecimento de forjados, a partir de 1937. Assim também, o desenvolvimento de máquinas, como o martelo acionado com pressão de vapor na parte superior, nos Estados Unidos, ou o martelo de contragolpe, desenvolvido na Alemanha em 1931 e também as prensas mecânicas e hidráulicas tiveram um grande impulso.

Sob a pressão dos processos concorrentes como fundição, sinterização, conformação maciça a frio, houve a necessidade do desenvolvimento, no sentido de economia de material e com espessuras de rebarba cada vez menores. O desenvolvimento dos processos de extrusão, recalque, laminação transversal e processos de forjamento automático, impulsionaram novos estudos na área de lubrificantes, aços especiais, novos controles no processo, objetivando vida de componentes e resistência mecânica maior das máquinas e equipamentos, assim como, das ferramentas. 
O estudo das variáveis de processo, encontra um aliado forte no desenvolvimento de análises computacionais e da simulação do forjamento, perguntas que eram difíceis de serem respondidas ou compreendidas agora começam a serem tratadas de forma científica, deixando-se as técnicas empíricas e passando-se para o estudo técnico destas variáveis.

\subsection{Visão Futura do Forjamento}

De acordo com a "Forging Industry Association" (FIA, 1998), a indústria de forjado é atualmente um elo importante na cadeia industrial, só nos Estados Unidos o forjado aparece em $20 \%$ dos produtos que representam o PIB daquele país, sendo uma parte essencial e estratégica da economia.

Nos últimos anos, houve nos Estados Unidos e na Europa uma queda significativa na indústria de forjado, em função de vários fatores, como competição mundial, mudanças de tecnologia, pressões ambientais, fatores econômicos e humanos.

As empresas que sobreviveram a estas mudanças estão emergindo melhores equipadas e adaptadas às mudanças do mercado mundial e das novas demandas dos clientes. Uma visão do futuro da indústria de forjado deve considerar os seguintes aspectos:

- Aumento da competição de um mercado global.

- Aumento no investimento em tecnologia e a pressão crescente para o retorno rápido do capital aplicado.

- Expectativa dos clientes, por aumento nos níveis de qualidade e redução nos custos. 
- Mudanças nas exigências de habilidades da mão de obra, com maior qualificação.

- Aumento na responsabilidade ambiental, de segurança da indústria e dos empregados.

- Melhor desempenho dos recursos energéticos.

Importantes esforços vem sendo aplicados com a colaboração dos vários setores tais como, forjarias, fornecedores, clientes, universidades e laboratórios de pesquisa para obterem-se vantagens competitivas e maximizar a eficiência na utilização dos recursos. Desta forma, é possível obter-se uma redução nos custos operacionais e proporcionar o avanço tecnológico necessário para se atuar neste mercado.

As áreas tecnológicas importantes para o forjamento que passam por significativos avanços são:

- Materiais.

- Projeto de ferramentas.

- Lubrificação.

- Modelagem.

- Otimização de processos por simulação computacional.

- Controle e monitoramento de processos.

- Manutenção preventiva e preditiva.

- Equipamentos.

- Automação. 
A forjaria do futuro deve buscar eficiência no uso da energia do processo e na proteção ao meio ambiente. Sua capacidade operacional, irá depender de uma efetiva integração dos recursos tecnológicos, ambientais e humanos.

Devido ao fato do forjamento não ser um processo amigável, as forjarias devem estruturar-se para atrair recursos humanos e manter sua força de trabalho em um processo de constante atualização e motivação, visando obter resultados efetivos dos investimentos aplicados.

A maior participação nos projetos dos produtos, por exemplo, com maior integração entre forjarias e montadoras ou fabricantes de motores, será um fator diferencial nos próximos anos.

\subsection{O Forjamento na Indústria Automotiva}

O forjado representa um importante segmento na cadeia de fornecedores da indústria automotiva, as propriedades dos forjados garantem uma condição ideal para determinados tipos de peças, que necessitam de alta resistência e possuem geometrias complexas.

Ao longo dos anos, houve uma sensível redução no peso e na quantidade de peças forjadas embarcadas nos veículos automotivos, devido ao avanço no uso de peças fundidas e também no uso de outros tipos de materiais, que não o aço. Porém a necessidade de peças mais complexas e resistentes nas suspensões dos veículos e dos motores com melhor performance, trabalho em regimes de rotações maiores e novos limites de emissões, principalmente no segmento diesel, impõem o uso de peças forjadas.

Esta exigência do mercado, faz com que a indústria de forjado esteja em constante 
desenvolvimento no uso de novos tipos de aço, na confecção de ferramentas e no processo produtivo.

A pressão por menores custos, maior qualidade dos produtos, vem sendo uma constante na relação entre as forjarias e as montadoras. Este fato, faz com que toda técnica e experiência milenar do processo de forjamento estejam em pleno desenvolvimento e devido a essa pressão, justifica-se toda investigação tecnológica capaz de contribuir neste sentido.

\subsection{Variáveis do Processo de Forjamento}

De acordo com Altan, Oh e Gegel (1999) as variáveis mais significativas no processo de conformação são:

\section{RELATIVAS AO MATERIAL DO TARUGO}

- Tensão de escoamento como função da deformação, taxa de deformação, temperatura e microestrutura.

- Conformabilidade como função da deformação, taxa de deformação, temperatura e microestrutura (curvas limites de conformação).

- Condições superficiais.

- Propriedades termo-físicas.

- Condições iniciais (composição química, temperatura, estados anteriores da microestrutura).

- Efeitos de mudança na microestrutura e composição química na tensão de escoamento e conformabilidade. 
RELATIVAS AO FERRAMENTAL

- Geometria das ferramentas.

- Condições superficiais.

- Material, dureza, tratamento térmico.

- Temperatura.

- Rigidez e precisão.

\section{RELATIVAS ÀS CONDIÇÕES DA INTERFACE FERRAMENTA-PEÇA}

- Tipo de lubrificante e temperatura de trabalho.

- Isolamento e características de resfriamento na camada de interface.

- Lubrificação e tensão de cisalhamento de atrito.

- Características relacionadas à aplicação e remoção do lubrificante.

\section{RELATIVAS A ZONA DE DEFORMAÇÃO}

- Mecanismo de deformação, modelo usado para análise.

- Fluxo de metal, velocidade, taxa de deformação, deformação (cinemática).

- Tensões (variações durante a deformação).

- Temperatura (geração e transferência de calor).

\section{RELATIVAS AOS EQUIPAMENTOS USADOS}

- Velocidade/razão de produção.

- Força/capacidade de conversão de energia.

- Rigidez e precisão. 
RELATIVAS AO PRODUTO

- Geometria.

- Precisão dimensional e tolerâncias.

- Acabamento superficial.

- Microestrutura, propriedades mecânicas e metalúrgicas.

RELATIVAS AO AMBIENTE

- Capacidade da mão-de-obra disponível.

- Poluição do ar, sonora e resíduos líquidos.

- Controle da produção e equipamentos disponíveis na fábrica.

\subsection{Atrito na Conformação Plástica}

As noções de atrito e seus efeitos são conhecidos da humanidade há muitos séculos, ao longo dos anos, muitos artifícios foram criados para reduzir esforços na execução de determinados trabalhos, como exemplo a movimentação de massas muito grandes para construções de edificações, ou para reduzir desgaste de corpos em contato com movimento rotativo. Em um resgate histórico do atrito Sinatora (2005), mostrou que o estudo do atrito está documentado desde o final do século XIV nos trabalhos de Leonardo da Vinci. Reconhecendo também a ele a primeira formulação do conceito de coeficiente de atrito como relação entre a força de atrito $(F)$ e a força normal $(P)$, sendo:

$\mu=\frac{F}{P}$ 
Em trabalhos desenvolvidos independentemente por Amonton e Coulomb nos séculos XVII e XVIII chegou-se a mesma formulação que é ainda, a base para o estudo do atrito de corpos rígidos ou que não sofrem deformação plástica macroscópica.

De acordo com Schey (1984), o efeito do atrito na conformação de metais, é feito mediante uma visão muito simplificada da interface ferramenta/material (material se refere neste contexto ao material que está sendo conformado pela ação da ferramenta). Avitzur (1995) externa que, em particular, os valores de atrito são muito difíceis de se determinar devido a complexidade dos fenômenos e devido a dificuldade de se medir a máxima tensão de cisalhamento dos materiais. Provavelmente o autor se refere à dificuldade de medida da máxima tensão de cisalhamento nas complexas (e indeterminadas) condições de tensão características de cada geometria de ferramenta, de cada par ferramenta/material ou das particulares formas de aplicação de força do equipamento de conformação plástica. Avitzur (1995) explicita, adequadamente, que devido à complexidade do fenômeno não se empregará o valor da força de atrito e sim um valor aparente resultante das múltiplas interações ferramenta material em cada uma das condições de conformação plástica. Em decorrência o autor estabelece que a determinação das forças de atrito seja feita para cada processo de fabricação específico. Uma primeira abordagem para a tensão na interface requer:

- Que se postule que a tensão ao longo da interface seja constante ao longo de toda a superfície de contato, citado por Avitzur (1995).

- O fluxo de metal no estado plástico deverá resultar na mudança de forma sem a fratura do corpo. 
- Que o coeficiente de atrito seja constante, Avitzur (1995) e Schey (1984).

Assim sendo, pode-se calcular o coeficiente de atrito $(\mu)$. como sendo:

$\mu=\frac{F}{P}=\frac{\tau_{i}}{p}$

aonde $\left(\tau_{i}\right)$ é a tensão de cisalhamento de atrito média na interface e ( $p$ ) é a pressão normal.

Neste caso onde exige-se que $(\mu)$ seja constante, a tensão de cisalhamento de atrito na interface $\left(\tau_{i}\right)$ deve aumentar na mesma taxa de pressão na interface $(p)$.

A constância do coeficiente de atrito requer que o crescimento da força normal seja acompanhado pelo crescimento da área real de contato o que foi demonstrado na década de 1960 por Bowdem e Tabor (1964). O crescimento da área real de contato ocorre inicialmente pela deformação plástica das asperezas mais altas e em seguida mediante a deformação de asperezas sucessivamente menores. Entretanto, no caso dos processos de conformação plástica o crescimento da força normal leva a interferência entre as asperezas que se deformam de modo que o crescimento da área real pode não ser mais linear com a elevação da força normal. Em uma etapa posterior do processo, a tensão normal passa a ser tão elevada que o material acaba por escoar. Em outras palavras, parte da energia devida a aplicação da força normal não será mais empregada para vencer a resistência devida a força de atrito mas sim empregada para deformar plasticamente o material. Assim sendo se terá a elevação da força normal não acompanhada pela correspondente elevação da força tangencial, como requerido pela aproximação da equação 2 e as restrições acima. Em decorrência o atrito aparente passa a diminuir com a elevação da força normal como 
mostra a figura 6. Assim que o escoamento macroscópico do material se inicia a interface ferramenta/material se imobiliza. Esta imobilidade "sticking" não significa que ocorreu necessariamente adesão "adhesion" ou "sticking" na interface.

O fato de ter-se atingido a tensão de escoamento local e a queda do coeficiente de atrito aparente levou a uma outra formulação para o coeficiente de atrito, renomeado para fator de cisalhamento de atrito $(m)$.

Neste modelo considera-se que o valor máximo da tensão de cisalhamento $\left(\tau_{i}\right)$ será chamada de $(K)$, conforme a figura 5 . Assim, a equação (2) pode ser escrita como:

$\tau_{i}=\mu p>k$

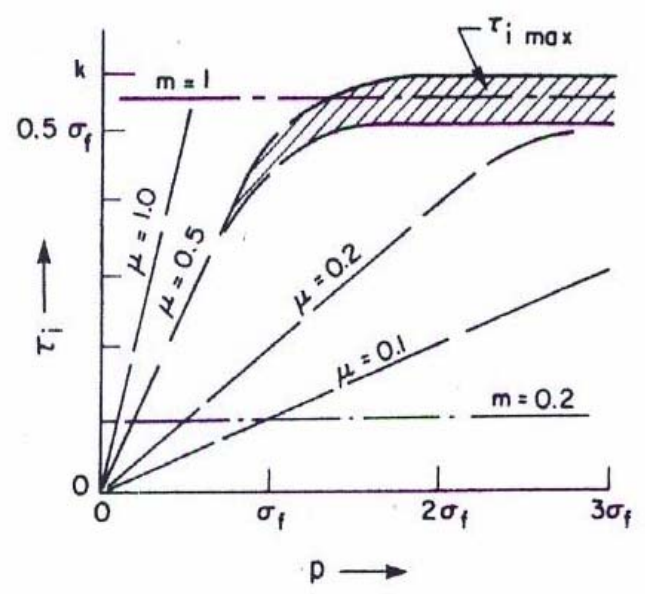

Figura 5: Tensão tangencial em função da pressão normal. Os valores do coeficiente de atrito $(\mu)$, bem como valores do fator de cisalhamento $(m)$, obtido de Schey (1984)

Os textos básicos de Avitzur (1995) e Schey (1984) adotam para a análise de $(K)$ a hipótese de que o estado de tensão na interface é uniaxial. Em decorrência:

- $K=0,577 \sigma_{f}$ para o critério de escoamento segundo Von Mises, onde também é dito: $\mu_{\max .}=0,577$. 
- $K=0,5 \sigma_{f}$ para o critério de escoamento segundo Tresca.

Onde $\left(\sigma_{f}\right)$ é a tensão de escoamento à compressão. Sem dúvida é possível melhorar a análise do estado de tensão, a exemplo do tratamento que se emprega na análise do contato real entre asperezas no modelo conhecido como de crescimento de junções, conforme Hutchings (1992).

Porém, como já se discutiu anteriormente, em muitos casos da conformação de metais, a pressão na interface $(p)$, assume valores maiores que a tensão de compressão $\left(\sigma_{f}\right)$, isto pois, para metais $(K)$ permanece constante com o aumento da pressão hidrostática. Nesta condição, teremos, segundo Schey (1984), valores irreais de $(\mu)$, definindo-se uma região onde não faz sentido definirmos atrito, pois teremos a aderência da peça, figura 6 .

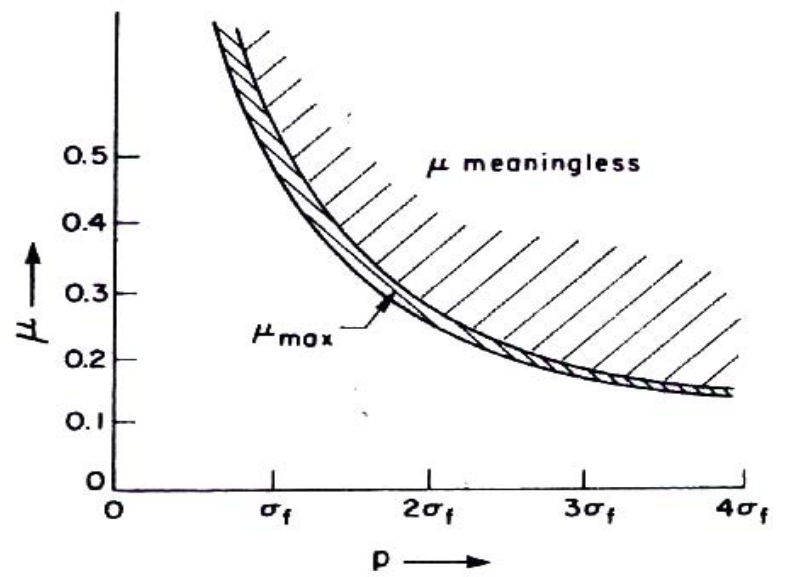

Figura 6: Variação do coeficiente de atrito $(\mu)$ com a pressão normal (p), gráfico, obtido de Schey (1984)

Esta consideração sobre a irrealidade do coeficiente de atrito, parece tratar de uma inadequação do modelo em prever resultados de medidas de atrito, uma vez que não há razão física para que o coeficiente de atrito não possa diminuir com elevação da força normal ou mesmo com a elevação de tensões triaxiais. Estas variações 
ocorrem, por exemplo em polímeros, conforme Hutchings (1992) e na soldagem por atrito de metais. Adicionalmente o modelo não trata do fenômeno de atrito que ocorre na interface real ferramenta/material e sim de um atrito aparente conforme restrições do próprio modelo. Em outras palavras o desconforto que os autores manifestam com a queda do coeficiente de atrito com a elevação da pressão (ou força normal) parece não proceder.

Entretanto, optou-se por contornar esta dificuldade (aparente), de se trabalhar com o coeficiente de atrito $(\mu)$ na interface matriz, peça e em condições de altas pressões, mediante o tratamento da variação da tensão de cisalhamento da interface como:

$\tau_{i}=m k$

Onde $(m)$, é o fator de cisalhamento de atrito e $m=0$, quando a interface está sem atrito nenhum enquanto que $m=1$ quando existe uma condição de aderência entre a matriz e peça.

Segundo Schey (1984), a esta definição atribui-se grande conveniência matemática, pois a tensão de cisalhamento $\left(\tau_{i}\right)$ é agora definida com a ajuda de $(K)$, que é constante. O autor indica que a determinação de $(p)$ seria dependente do valor do coeficiente de atrito que, por sua vez seria dependente de $(p)$. Esta análise, parece esquecer a hipótese de complexidade da força de atrito e da necessidade de determinar-se esta força experimentalmente como se explicitou no início deste tópico.

$\mathrm{Na}$ interface metal matriz, haverá a ocorrência de variações de pressão, velocidade de deslizamento, temperaturas e outras condições assim sendo é de se esperar uma variação de $(m)$ ou de $(\mu)$. Por conveniência, usa-se uma média destes fatores para 
cálculo. Isto é bem aceito para cálculo de força, porém para o cálculo das tensões distribuídas pode trazer erros.

Combinando-se as equações (2) e (3), obtém-se:

$\tau_{i}=\mu p=m K$

$\mu p=m \frac{\sigma_{f}}{2} \quad$ segundo Tresca.

Assim, quando $p=\sigma_{f}$ tem-se $m=2 \mu$ e para $\mathrm{p}=2 \sigma_{f}$ tem-se $m=4 \mu$

Sendo possível dizer, que as diferenças entre os dois tratamentos crescem com o aumento da pressão na interface.

Avitzur (1995) considera um terceiro modelo para se determinar-se a força de atrito na interface ferramenta/material, no caso de existir um filme lubrificante separando por inteiro a peça da ferramenta. Neste caso, os parâmetros $(\mu)$ ou $(m)$, seriam substituídos pela viscosidade do lubrificante, enquanto a tensão de cisalhamento seria expressa pelo produto da viscosidade pela taxa de deformação por cisalhamento do lubrificante.

$\tau_{i}=\sigma_{s}=\eta \gamma$

Onde $(\eta)$ é a viscosidade e $(\dot{\gamma})$ é a taxa da tensão de cisalhamento.

Os dois modelos explicitados pelas equações 2 e 4 são empregados nos softwares de simulação de forjamento inclusive no FORGE 3 (2004), entre outros. 


\subsection{Métodos Experimentais para Determinação do Atrito}

O atrito pode ser determinado através de duas formas distintas que são:

a) Método de medição direta.

O método de medição direta consiste em medir-se as tensões de cisalhamento de atrito $\left(\tau_{i}\right)$ e a tensão normal $(\sigma)$ na superfície de contato entre o corpo de prova e as matrizes. Esta medição é feita através da medida de deformações com extensômetros. Este método possibilita o conhecimento direto das tensões $\left(\tau_{i}\right)$ e $(\sigma)$ e do coeficiente de atrito em pontos específicos da matriz. Desta forma pode-se fazer uma avaliação do comportamento do coeficiente de atrito ao longo de uma superfície.

Sua desvantagem está no grau de complexidade dos dispositivos e equipamentos exigidos.

b) Método de medição indireta.

A medição indireta do atrito pode ser feita de várias formas e o emprego de um determinado método depende do conhecimento das variáveis do processo de forjamento, para que a escolha do método possa representar e simular as condições reais deste processo.

Um método muito conhecido e aplicado para determinação do coeficiente de atrito, em condições de deformação plástica, é o método do anel, que consiste na deformação de corpos de prova em forma de anéis com superfícies planas e com medidas padronizadas. Submetendo-se este corpo de prova a uma carga, que leve o anel a uma dada redução de altura, teremos uma variação em seus diâmetros interno e externo. Esta variação é dependente da condição de atrito, existente no contato do corpo de prova, com a superfície das matrizes, contra as quais, se exercem as forças 
de compressão. Se o atrito fosse igual a zero, o anel se comportaria como se fosse um disco sólido, ou seja, todos elementos do anel fluiriam radialmente para fora, a uma taxa proporcional à sua distância do centro, neste caso teríamos um aumento no diâmetro interno do anel. Com o aumento do atrito, haverá uma redução no diâmetro interno do anel, isto pois, haverá o surgimento de uma região de transição, onde parte do material irá escoar radialmente, no sentido interno do anel e parte do material irá escoar radialmente para fora do anel. Esta região é chamada de superfície neutra e está indicada na figura 7.

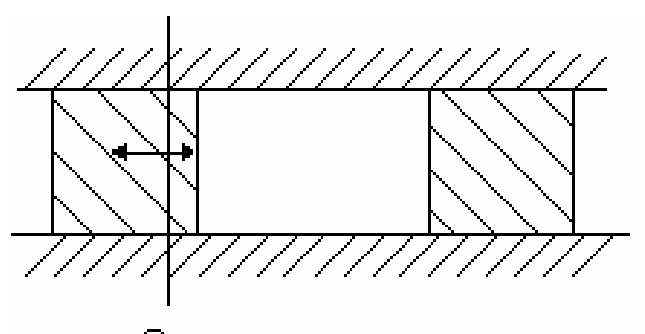

Sn

Figura 7: Indicação da superfície neutra no forjamento do anel.

A vantagem deste teste é que não há necessidade de conhecer-se a força para deformação do anel, nem a tensão de escoamento do material do corpo de prova, para determinação do coeficiente de atrito.

\subsection{O Ensaio do Anel}

A técnica para se determinar o coeficiente de atrito por meio do ensaio do anel, como descrito acima, foi desenvolvida por Male e Cockroft (1964). Neste trabalho foi proposta a determinação do coeficiente de atrito, baseada na conformação de anéis (alumínio, cobre, bronze, aço carbono e titânio), com dimensões padronizadas. O objetivo do desenvolvimento desta técnica é que os resultados obtidos não 
dependeriam das propriedades mecânicas do material, mas sim da deformação geométrica do anel e poderia ser aplicada em uma vasta gama de condições de temperatura, velocidade de deformação, condição de lubrificação e condições das matrizes. Esta flexibilidade é muito importante quando se estuda a influência das variáveis do processo de forjamento a quente no coeficiente de atrito. A técnica apresentada é basicamente experimental e seus resultados foram obtidos criando-se curvas chamadas de calibração, para cada material, aonde o coeficiente de atrito $(\mu)$ é relacionado com a variação do diâmetro interno e com a variação da altura do anel.

Neste trabalho foram obtidas curvas comparativas, da variação do coeficiente de atrito, com a temperatura para os diversos materiais, sem o uso de lubrificação das matrizes. Destas curvas pode-se observar que para o alumínio, latão alfa, cobre e aço carbono, o coeficiente de atrito não apresenta variações entre a temperatura ambiente, até temperaturas próximas de $150^{\circ} \mathrm{C}$. Porém próximo deste ponto existe um aumento do coeficiente de atrito com a temperatura. No aço e no cobre esta elevação segue até um ponto entre 720 a $750^{\circ} \mathrm{C}$, aonde começa a haver uma redução do coeficiente de atrito seguindo-se até a temperatura de $1000^{\circ} \mathrm{C}$, que foi o limite do ensaio. Este fato, evidencia que a natureza do material afeta o comportamento do coeficiente de atrito com a variação de temperatura. Os resultados podem ser vistos na figuras 8 . 


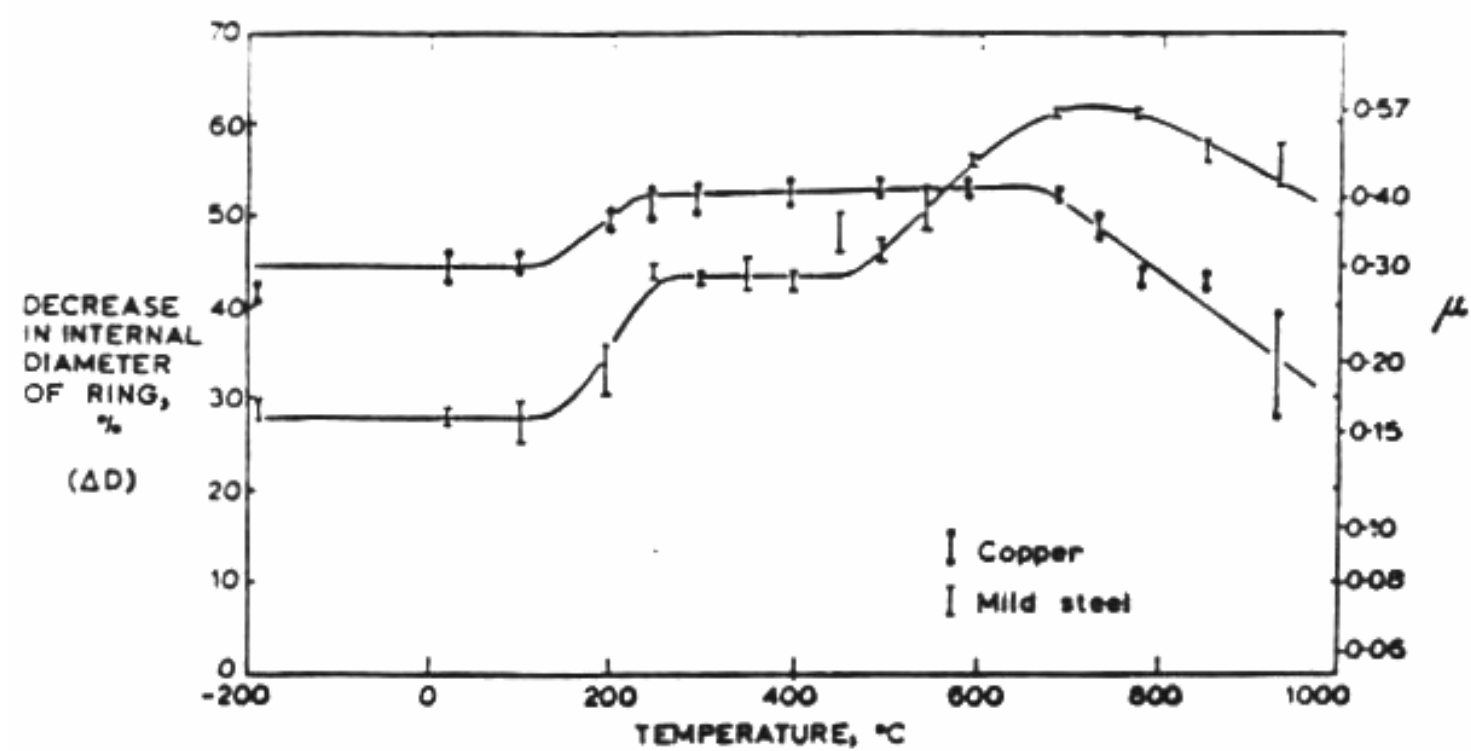

Figura 8: Gráfico com as variações de coeficiente de atrito $(\mu)$ com a temperatura para o cobre e para o aço carbono, obtido de Male e Cockroft (1964)

\subsubsection{Fatores que Podem Influenciar no Coeficiente de Atrito}

Em trabalho posterior, Male (1966) verificou-se a influência das condições da superfície entre as amostras e as matrizes no ensaio do anel. Foram feitos estudos (com alumínio, titânio, latão alfa sem lubrificação e latão alfa lubrificado), em temperatura ambiente, variando-se a velocidade da prensa $(0,0025 ; 2 ; 300$ pol./seg.) e o tipo de lubrificante (grafite como lubrificante sólido, lanolina como lubrificante sólido mole e parafina como lubrificante líquido). Verificou-se que em condições de temperatura ambiente, o coeficiente de atrito do latão alfa, resultou um pouco menor que o coeficiente de atrito do cobre. Isto pode ser possível pela presença de zinco no latão alfa.

Para se determinar este efeito, foram feitos ensaios com anéis feitos de uma série de ligas de cobre-zinco. Foi verificada uma dependência direta do coeficiente de atrito com o teor de zinco na liga de material. Ilustrado na figura 9. 


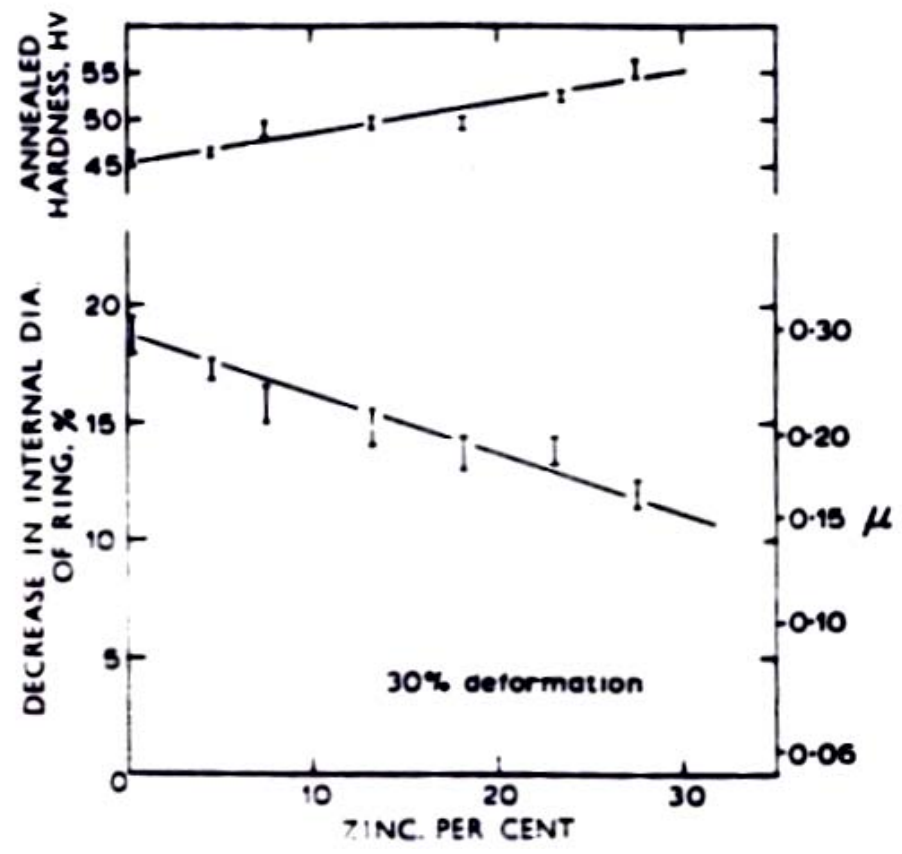

Figura 9: Gráfico com a influência do teor zinco em ligas de cobre, no coeficiente de atrito ( $\mu$ ), obtido de Male (1966)

Como conclusões deste trabalho, foi verificado que:

1) Em temperatura ambiente, o efeito da taxa de deformação no coeficiente de atrito é controlado pela quantidade de contaminantes na superfície de contato entre a matriz e o anel, e pelo filme de óxido presente na amostra do anel.

2) Para o ensaio a seco, ou com um lubrificante sólido, a velocidade da prensa não tem efeito sobre o coeficiente de atrito. Entretanto quando se usa um lubrificante sólido mole ou um lubrificante líquido, um aumento na velocidade da prensa aumenta a eficiência da lubrificação, promovendo uma camada grossa de lubrificante e possibilitando o aumento da taxa de deformação antes da ruptura desta camada.

Em seu trabalho, Wang e Lenard (1992) fizeram uma série de experimentos com anéis em aço ligado ao $\mathrm{Nb}$ e $\mathrm{V}$. Os anéis ensaiados tinham as proporções de 6: 3:2, para os diâmetros externos, internos e altura respectivamente e foram normalizados a 
uma temperatura de $1000^{\circ} \mathrm{C}$ antes dos ensaios. A temperatura usada para os ensaios foi entre 900 e $975^{\circ} \mathrm{C}$ e como lubrificante foi usado o Deltaglaze 19, que é um lubrificante à base de vidro. As taxas de deformação usadas no ensaio foram de 0,$005 ; 0,05 ; 0,5 ; 5 \mathrm{~s}^{-1}$

Os resultados foram inseridos, em um gráfico, com a curva de calibração obtida por um método analítico baseado no modelo de Avitzur conforme indicado na figura 10 .

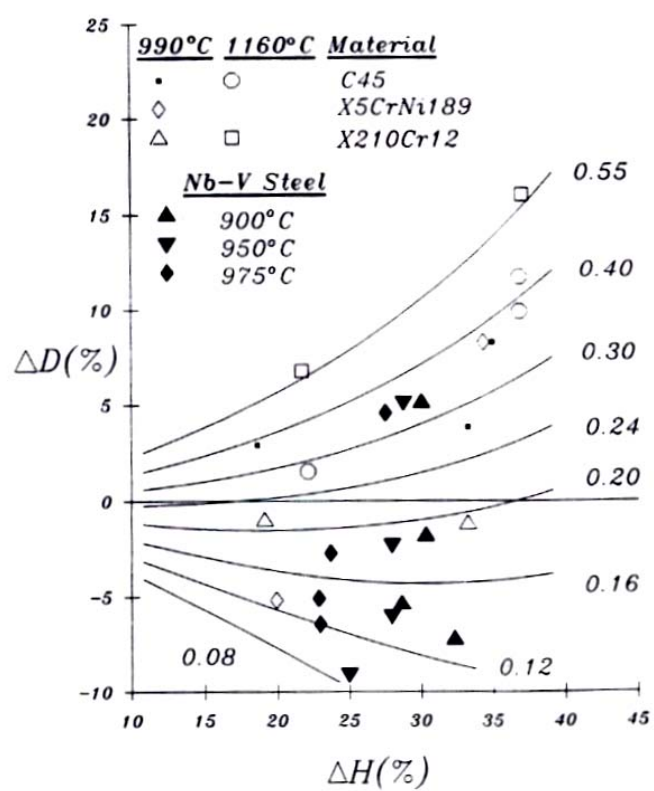

Figura 10: Gráfico com fator de cisalhamento de atrito $m$, de vários tipos de aço em uma curva de calibração analítica, obtido de Wang e Lenard (1992)

Como resultado, foi verificado que a taxa de deformação, temperatura e a formação de carepa, são os parâmetros mais significativos no forjamento do anel e interferem diretamente no fator de cisalhamento de atrito $(m)$.

Foi verificado também que destes fatores, a formação de carepa é o fator mais significativo. 


\subsubsection{A Abordagem Analítica do Ensaio do Anel}

Hawkyard e Johnson (1967), desenvolveram a primeira abordagem analítica para o ensaio do anel, foi feita uma comparação entre as curvas teóricas, obtidas por este método analítico e as curvas experimentais obtidas, por Male e Cockroft (1964), conforme mostrado na figura 11.

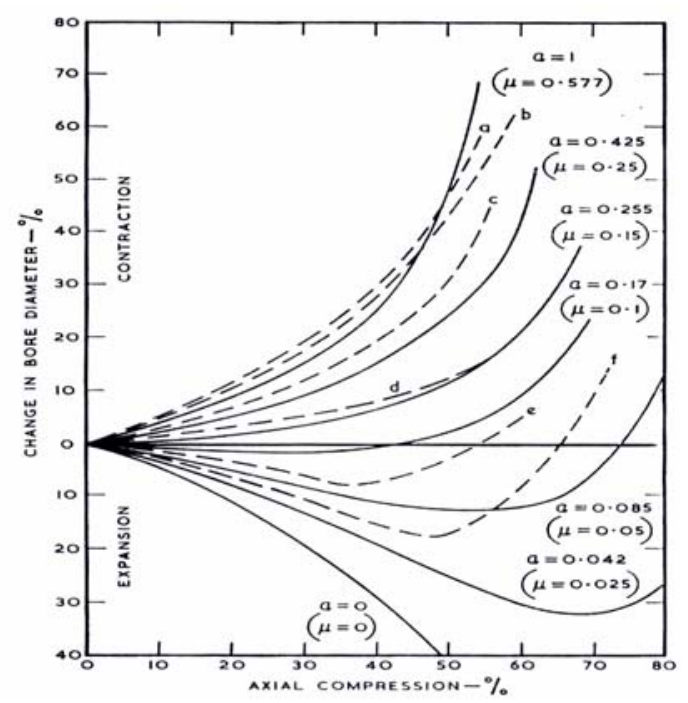

Figura 11: Gráfico comparativo com valores teóricos (linha cheia) do coeficiente de atrito $(\mu)$ ou do fator de cisalhamento de atrito $(m)$, no gráfico representado por $(\alpha)$ onde $\alpha p=\mu k$, com valores experimentais (linha tracejada) para os materiais: a) aço sem lubrificante, b) cobre sem lubrificante, c) aço sem lubrificante e matrizes polidas, d) cobre lubrificado com grafite, e) latão lubrificado com lanolina, f) alumínio lubrificado com parafina obtido de Hawkyard e Johnson (1967)

Verificou-se que as formas das curvas teóricas, apresentaram uma boa concordância com as curvas experimentais, obtidas por Male e Cockroft (1964).

Também foi verificado que para valores do coeficiente de atrito $(\mu)$ maiores que 0,15 ou próximos à região de aderência onde $\mu=0,577$; ocorre um bom ajuste entre as predições do modelo analítico com os experimentos de Male e Cockroft (1964), e que há uma dispersão maior na região de baixo atrito e grandes deformações. 
Neste trabalho também, foi apresentado um método analítico para se determinar as mudanças geométricas que ocorrem na compressão do anel, e o aparecimento da superfície neutra demonstrada na figura 7.

\subsubsection{Novas Visões do Ensaio do Anel}

A evolução dos programas de simulação do processo de conformação, usando métodos de elementos finitos, trouxe a necessidade de se obter maior conhecimento sobre as condições do atrito na interface entre matriz e a peça.

Esta necessidade incentivou novas pesquisas sobre o ensaio do anel e busca-se uma melhor adaptação dos modelos de atrito inseridos nos programas com os valores obtidos experimentalmente. Neste sentido, novas geometrias começaram a ser testadas e seus resultados comparados com os ensaios executados, usando-se o modelo convencional de anel.

Em 1997 foi apresentado, um trabalho com uma série de simulações feitas usando-se o modelo de atrito desenvolvido por Wanhein-Bay, neste trabalho Petersen, Martins e Bay (1997), propõem, que pode se escrever a equação do atrito como sendo:

$$
\tau_{i}=f \alpha K
$$

Onde $(f)$ é o fator de atrito, podendo variar de 0 , condição sem atrito e $f=1$, se houver a condição de aderência e $(\alpha)$ é a relação entre a área de contato real e a área aparente entre a matriz e a peça. Na prática, o fator $(f)$ é obtido experimentalmente e ( $\alpha$ ) é calculado de acordo com expressões analíticas de Wanhein-Bay.

Os resultados deste trabalho, foram comparados com ensaios feitos com amostras em forma semicônica, com amostras de anéis na forma convencional e com amostras de 
anel de uma nova forma geométrica, conforme indicado na figura 12.

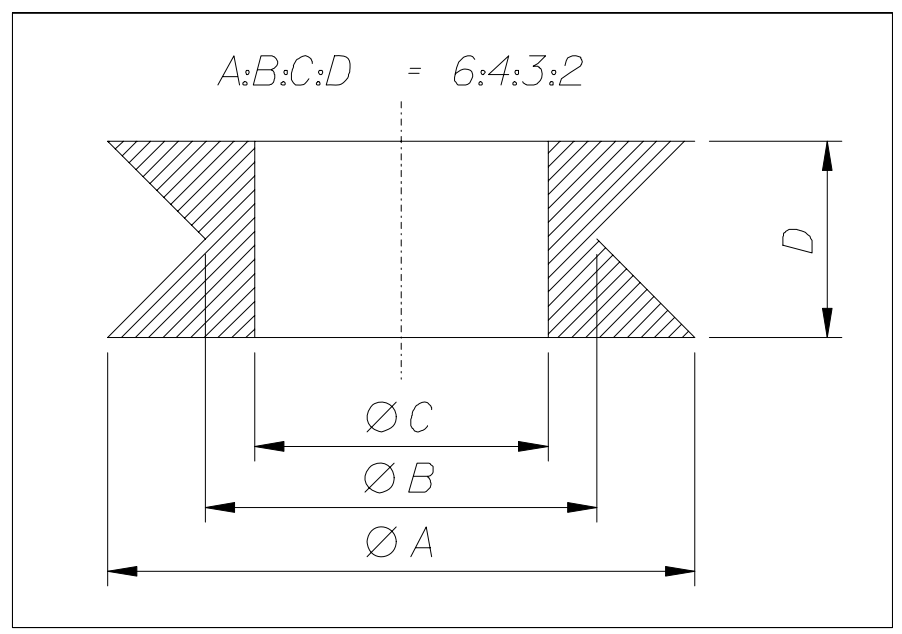

Figura 12: Geometria proposta para calibração do modelo de atrito em condições de baixos níveis de pressão normal adaptado de Petersen, Martins e BAY (1997)

Em todos os casos, as amostras foram feitas em E1CM alumínio puro e os ensaios foram feitos sem lubrificação.

Os resultados mostraram uma diferença dos valores obtidos do coeficiente de atrito, quando simulados usando-se o modelo de atrito da equação 4 e da equação 8 . Os autores consideram, o modelo da figura 12 do anel mais sensível para condições onde a pressão normal $(p)$ sobre a área de contato assume valores baixos $\left(\frac{p}{\sigma}<1\right)$, onde ( $p)$ é a pressão normal e $(\sigma)$ é a tensão normal.

Petersen, Martins e Bay (1998), deram continuidade aos experimentos e fazem novos ensaios comparando os resultados obtidos com o novo modelo de anel, mostrado na figura 12 , com os resultados obtidos através de ensaios com a forma convencional do anel. 
$\mathrm{Na}$ figura 13 é possível ver os resultados dos ensaios com anéis na forma convencional.

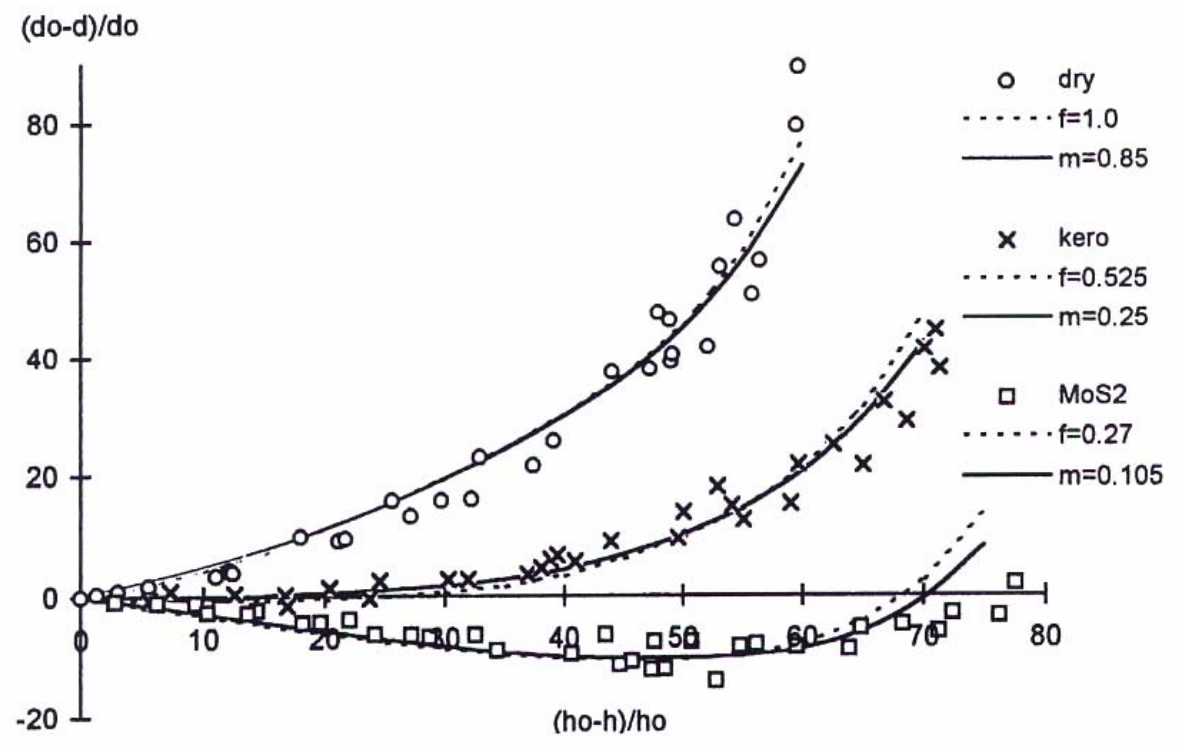

Figura 13: Ensaio do anel na forma convencional com as curvas de calibração obtidas em simulação com os modelos de atrito conforme equação 4 (linha cheia) e equação 8 (linha tracejada), conforme Petersen, Martins e Bay (1998)

As curvas de calibração foram obtidas fazendo-se a simulação pelo método de elementos finitos, levando-se em consideração os dois modelos de atrito (modelo da equação 4 e o modelo da equação 8). Porém, neste novo experimento foi levado em consideração o fator lubrificação, os ensaios foram feitos a seco e com dois lubrificantes, querosene e $\mathrm{MoS}_{2}$.

Os resultados dos ensaios do anel com a forma geométrica alterada, conforme mostrado na figura 12, podem ser vistos nas figuras 14 e 15 . Estes ensaios foram feitos nas mesmas condições do ensaio com a forma convencional do anel e o processo de simulação para obtenção das curvas de calibração foi o mesmo. 
(a)

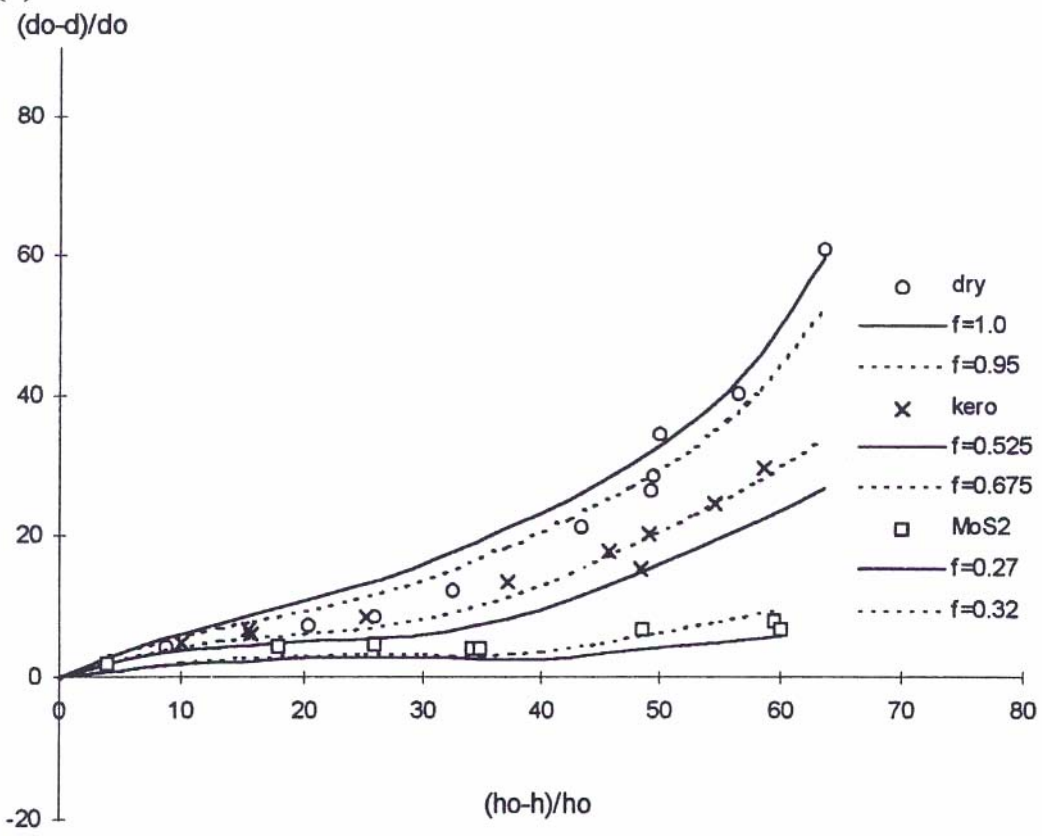

Figura 14: Ensaio do anel com forma de acordo a figura 12 e curva de calibração obtida com a simulação adotando-se o modelo de atrito conforme equação 8, conforme Petersen, Martins e BAY (1998)

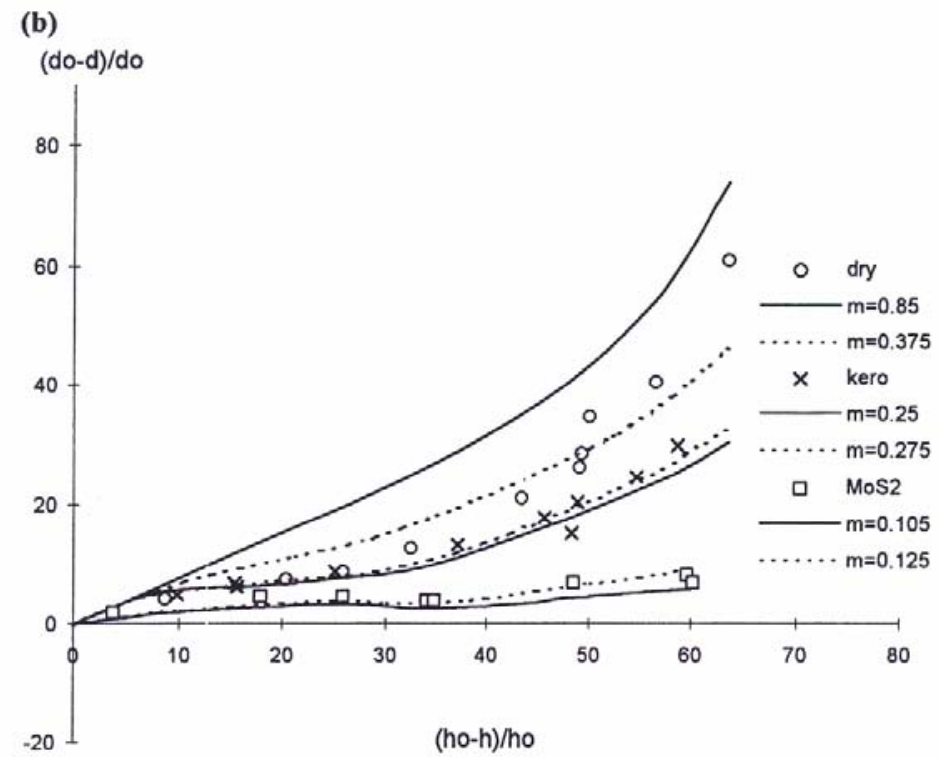

Figura 15: Ensaio do anel com forma de acordo com a figura 12 e curva de calibração obtida com a simulação adotando-se o modelo de atrito conforme equação 4 conforme Petersen, Martins e BAY (1998) 
Com os resultados obtidos, puderam-se fazer as seguintes observações:

- Para os ensaios com a forma convencional do anel, com os resultados demonstrados na figura 13, as curvas de calibração obtidas em ambos os modelos de atrito, não apresentam diferenças significativas e há boa convergência dos resultados práticos. Porém, observou-se uma maior dispersão, principalmente para altos valores de deformação na altura.

- Nos ensaios com a forma geométrica do anel modificada, conforme mostrado na figura 12 e indicados nas figuras 14 e 15, observou-se uma boa correspondência entre os resultados obtidos usando-se o querosene e o $\mathrm{MoS}_{2}$, e a curva de calibração obtida através do processo de simulação adotando-se os dois modelos de atrito (equações 4 e 8). Porém, os resultados dos ensaios feitos a seco mostraram-se mais próximos das curvas de calibração, adotando-se o modelo de atrito da equação 8. Reforçando a importância do conhecimento do modelo de atrito a ser adotado, em processos de simulação e também, a importância da comprovação deste modelo através de ensaios. 


\section{OBJETIVOS}

Verificar o efeito do material a ser forjado, do recobrimento da ferramenta, da temperatura de ensaio e da velocidade do mesmo, no coeficiente de atrito, empregando-se o ensaio de anel.

Verificar se a simulação do ensaio de anel por meio do programa FORGE 3 (2004) é capaz de reproduzir os resultados dos ensaios. 


\section{MATERIAIS E MÉTODOS}

Os ensaios do anel foram realizados nas dependências do Laboratório de Transformação Mecânica (LdTM) da Universidade Federal do Rio Grande do Sul em Porto Alegre (UFRGS).

Os equipamentos para realização dos ensaios foram:

- Uma prensa hidráulica universal com capacidade de $400 \mathrm{kN}$

- Um forno resistivo com capacidade de atingir temperatura máxima de $1260^{\circ} \mathrm{C}$.

- Instrumentos de medição

- Termopar

O conjunto de equipamentos usados no laboratório, pode ser visto na figura 16 :

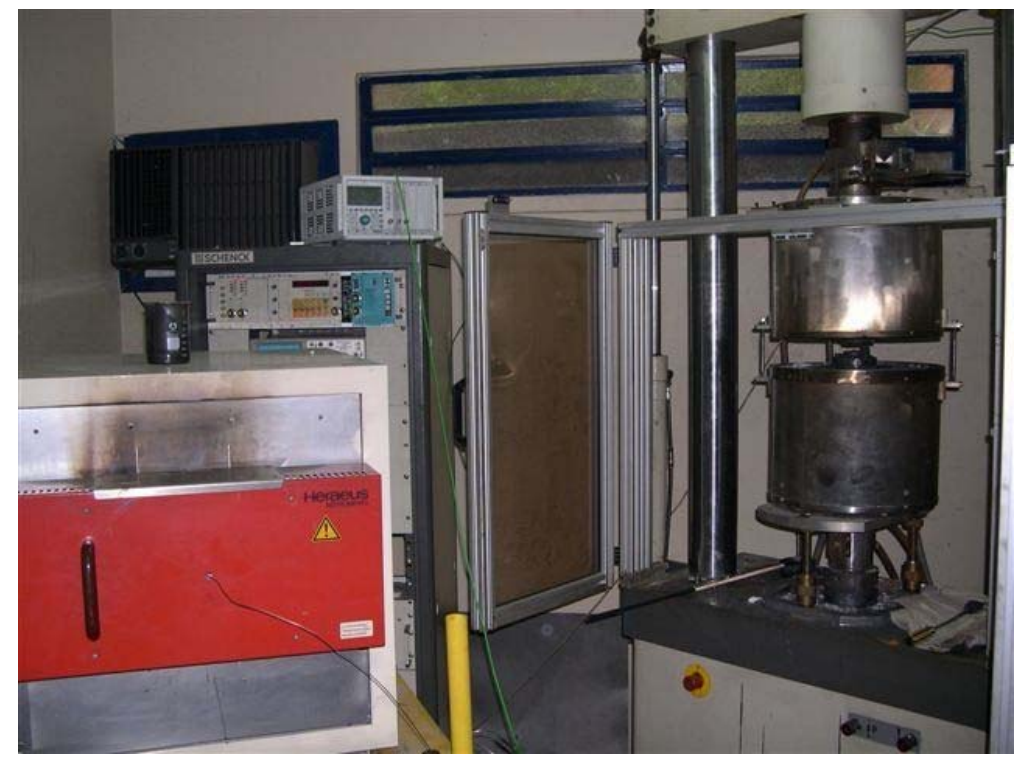

Figura 16: Conjunto para ensaio do anel, no LdTM da UFRGS. Forno, prensa e instrumentação. 


\subsection{Materiais}

\subsubsection{Materiais dos Anéis}

Os materiais utilizados na confecção dos anéis foram os aços:

- SAE 1548

- DIN 38MnSiVS5

Estes materiais, são usados normalmente em peças automotivas como virabrequins e bielas. As composições químicas destes aços estão indicados na tabela 1

Tabela 1: Composição química dos aços (\% em peso). Análise por espectrometria. Carbono por combustão

\begin{tabular}{|l|c|c|c|c|c|c|c|c|c|c|c|c|c|c|}
\hline \multicolumn{1}{|c|}{ Material } & C & Mn & Si & P & S & Al & V & N & Sn & Ni & Cr & Mo & W & Cu \\
\hline SAE 1548 & 0,530 & 1,400 & 0,350 & 0,025 & 0,025 & 0,045 & & & & & & & & \\
\hline DIN 38MnSiVS5 & 0,400 & 1,500 & 0,700 & 0,035 & 0,065 & 0,030 & 0,130 & 0,020 & 0,030 & 0,200 & & 0,060 & & 0,250 \\
\hline VPCW (Villares) & 0,350 & & 1,000 & & & & 0,250 & & & & 5,000 & 1,500 & 1,350 & \\
\hline
\end{tabular}

Não houve nenhum tipo de tratamento térmico nos anéis.

A geometria dos anéis obedece a proporção de 6:3:2, que é padronizada e largamente utilizada em ensaios de compressão com as medidas de diâmetro externo, diâmetro interno e altura dos anéis em milímetros, sendo: 30:15:10 $\mathrm{mm}$ respectivamente.

Os corpos de prova foram obtidos a partir de uma barra de material torneada e cortada no próprio torno. Não houve preparação das superfícies do corpo de prova no sentido de redução de sua rugosidade, para manter-se uma condição próxima da condição real de uso, em um ambiente industrial, onde normalmente, emprega-se corte por serra ou tesoura. 


\subsubsection{Materiais das Matrizes}

Foram preparados dois jogos de matrizes, com dimensões apropriadas para o trabalho, na prensa de $400 \mathrm{kN}$ do LdTM, com acabamento superficial normalmente utilizado no forjamento de peças automotivas.

Um dos jogos de matrizes feito em aço VPCW (Villares) com acabamento polido e com as seguintes rugosidades:

Matriz superior

- $R a=0,63 \mu \mathrm{m}$

- $R t=7,34 \mu \mathrm{m}$

Matriz inferior

- $R a=0,66 \mu \mathrm{m}$

- $R t=7,29 \mu \mathrm{m}$

O outro jogo de matrizes foi feito em aço VPCW (Villares), porém em sua superfície foi realizado um processo de revestimento com PVD obtendo-se as seguintes rugosidades:

Matriz superior

- $R a=0,56 \mu \mathrm{m}$

- $R t=5,75 \mu \mathrm{m}$

Matriz inferior

- $R a=0,51 \mu \mathrm{m}$

- $R t=6,52 \mu \mathrm{m}$ 
As medições de rugosidade foram feitas em um rugosímetro "Somicronic, Surfascan model UM2D”, da firma ThyssenKrupp Metalúrgica Campo Limpo.

\subsubsection{Lubrificante Usado no Experimento}

O lubrificante usado para os ensaios foi o Fixatan 58 da firma IGUCIMA, à base de grafite.

\subsection{Método do Experimento}

\subsubsection{Arranjo Experimental}

O experimento foi determinado, através da combinação das variáveis escolhidas como mais significativas, para o processo de forjamento a quente e foi feito um planejamento de experimento, através do programa MINITAB (2000), para se determinar o número mínimo de ensaios, que pudessem garantir uma confiabilidade no experimento. Como resultado deste planejamento de experimento, obteve-se uma combinação de 16 ensaios, conforme mostrado na tabela 2.

Tabela 2: Combinação das variáveis de processo

\begin{tabular}{|c|c|c|c|c|}
\hline Ensaio & $\begin{array}{c}\text { Velocidade } \\
(\mathrm{mm} / \mathrm{s})\end{array}$ & $\begin{array}{c}\text { Temperatura } \\
\left({ }^{\circ} \mathrm{C}\right)\end{array}$ & Revestimento & Material \\
\hline 1 & 2 & 800 & Polido & 1548 \\
\hline 2 & 15 & 800 & Polido & 1548 \\
\hline 3 & 2 & 1200 & Polido & 1548 \\
\hline 4 & 15 & 1200 & Polido & 1548 \\
\hline 5 & 2 & 800 & Revestido & 1548 \\
\hline 6 & 15 & 800 & Revestido & 1548 \\
\hline 7 & 2 & 1200 & Revestido & 1548 \\
\hline 8 & 15 & 1200 & Revestido & 1548 \\
\hline 9 & 2 & 800 & Polido & 38 MnSiVS5 \\
\hline 10 & 15 & 800 & Polido & 38 MnSiVS5 \\
\hline 11 & 2 & 1200 & Polido & 38 MnSiVS5 \\
\hline 12 & 15 & 1200 & Polido & 38 MnSiVS5 \\
\hline 13 & 2 & 800 & Revestido & 38 MnSiVS5 \\
\hline 14 & 15 & 800 & Revestido & 38 MnSiVS5 \\
\hline 15 & 2 & 1200 & Revestido & 38 MnSiVS5 \\
\hline 16 & 15 & 1200 & Revestido & 38 MnSiVS5 \\
\hline
\end{tabular}




\subsubsection{Procedimento Experimental}

Primeiramente, as ferramentas da prensa foram aquecidas à uma temperatura de $250^{\circ} \mathrm{C}$. Esta temperatura foi escolhida, por ser a temperatura média de trabalho de matrizes em processo de forjamento a quente, em peças de aço para indústria automotiva. Esta temperatura foi mantida durante os ensaios, através de um sistema de aquecimento por resistências elétricas, envolvendo tanto a matriz superior, quanto a matriz inferior, conforme mostrado na figura 17.

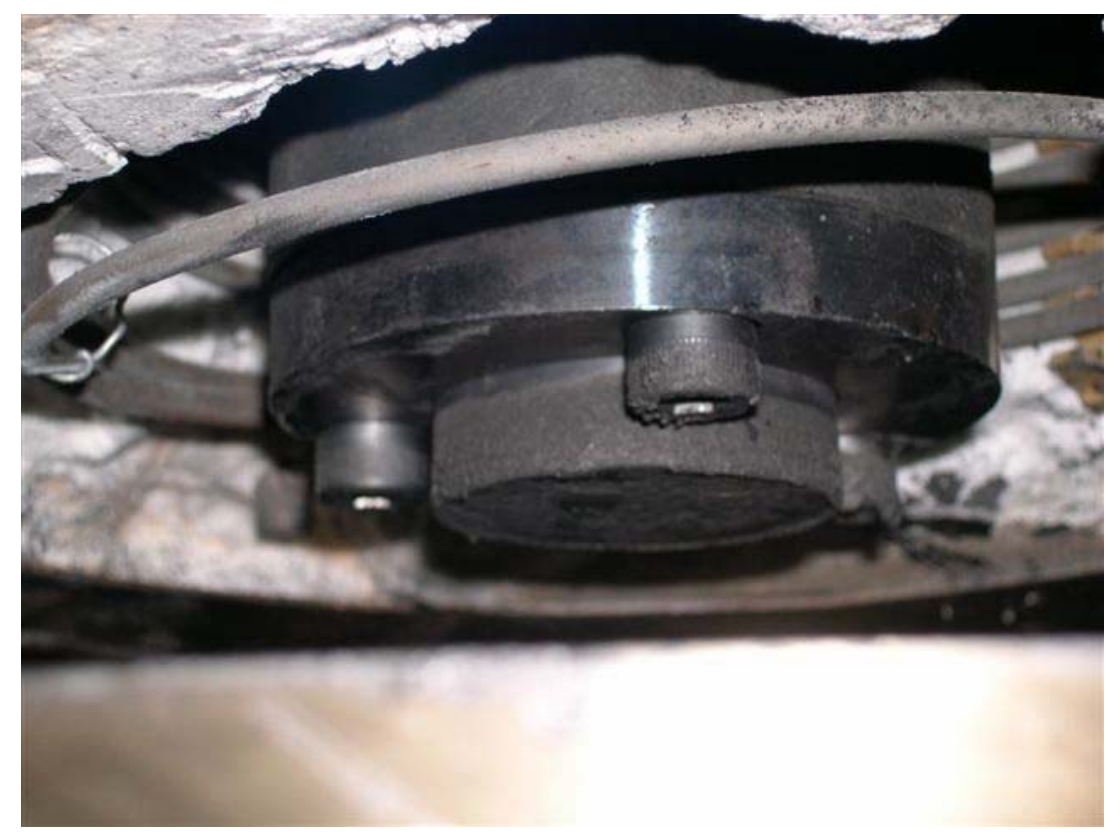

Figura 17: Matriz montada na prensa do LdTM da UFRGS para o ensaio de anéis com sistema de aquecimento.

O forno para aquecimento dos anéis, posteriormente foi ajustado para a temperatura do ensaio, um corpo de prova com um furo lateral e um termopar inserido até o meio da peça, foi colocado no forno.

A seguir, de posse de um cronômetro e de um indicador de temperatura acoplado ao 
termopar, determinou-se o tempo mínimo necessário, para que o corpo de prova atingisse a temperatura solicitada. Também, foi realizado um teste para a determinação do tempo máximo de permanência do corpo de prova dentro do forno, de modo que fosse reduzida a geração de carepa. Este procedimento foi adotado, para reduzir-se o efeito da carepa no ensaio (mas não funcionou muito bem, no sentido de prevenir a influência da carepa formada, no coeficiente de atrito). De acordo com estas medições, foi estabelecido o tempo necessário para aquecer o corpo-de-prova para os ensaios nas, temperaturas de $800^{\circ} \mathrm{C}$ e $1200^{\circ} \mathrm{C}$. Além disso, devido às características geométricas do corpo de prova, foi levado em conta, o tempo necessário para a retirada do mesmo do interior do forno e seu correto posicionamento na matriz para o ensaio, isto pois, ocorre uma queda de temperatura. Desse modo, estabeleceu-se, que para a realização dos ensaios a $800^{\circ} \mathrm{C}$, o corpo de prova deveria deixar o forno com aproximadamente $960^{\circ} \mathrm{C}$. Já para a realização dos ensaios a $1200^{\circ} \mathrm{C}$, o corpo deveria deixar o forno a $1260^{\circ} \mathrm{C}$.

Faltando aproximadamente 45 segundos para a retirada do corpo de prova do forno, as ferramentas foram adequadamente lubrificadas, com lubrificante à base de grafite e os sistemas de controle da prensa foram preparados para realização do ensaio. 


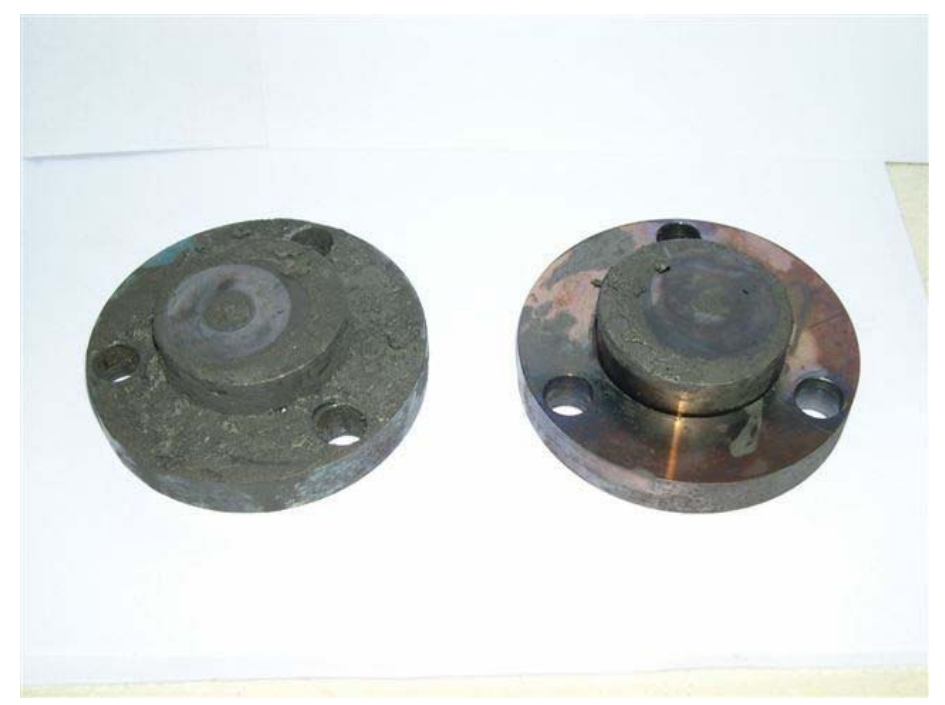

Figura 18: Matrizes usadas no ensaio de anéis,com marcas da região de apoio dos anéis.

Assim que o corpo de prova atingiu a temperatura estabelecida, o mesmo foi retirado do forno e levado à prensa, onde é feita a compressão dos anéis (figura 19).

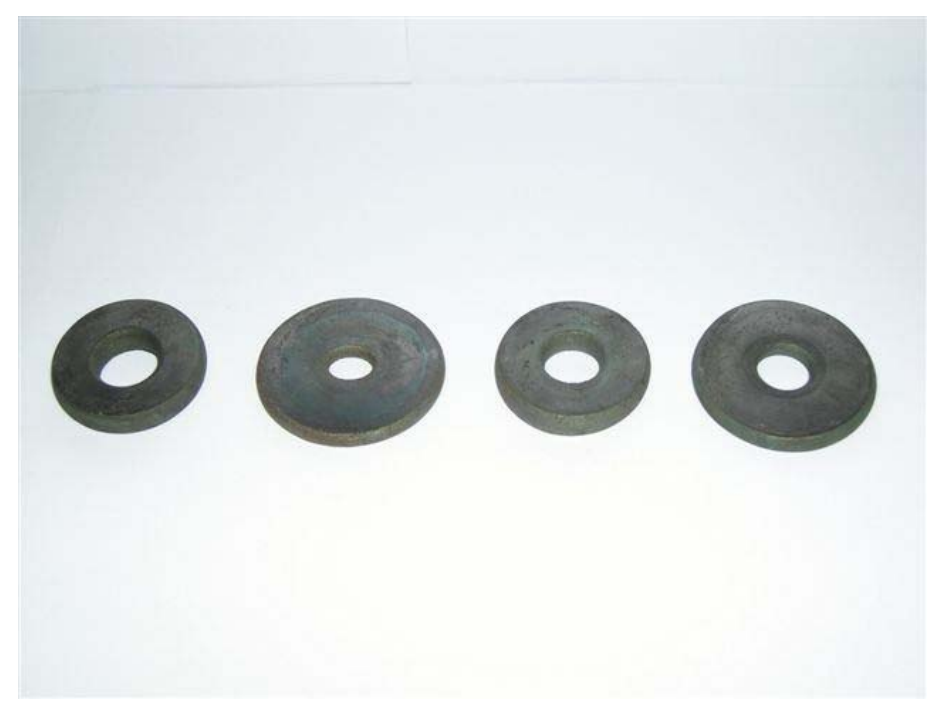

Figura 19: Amostras de anéis ensaiadas no LdTM da UFRG prensados.

Após a compressão dos anéis, estes foram resfriados em água (figura 19) e foram feitas as medições dos diâmetros internos e das alturas. Foram feitas três medições de 
cada diâmetro, adotado assim como valor, a media dos três pontos.

Alguns ensaios tiveram que ser repetidos, pois em algumas condições de velocidade da prensa e da temperatura do corpo de prova, houve o limite de carga da prensa, uma vez que sua capacidade é de $400 \mathrm{kN}$. Reduções muito grandes na altura dos anéis, também não foram possíveis de serem atingidas, em função da capacidade da prensa.

\subsubsection{Procedimento para Obtenção do Coeficiente de Atrito $(\mu)$}

O coeficiente de atrito foi obtido através da curva de calibração, gerada no processo de simulação do ensaio de compressão do anel, feita no programa FORGE 3 (2004), usado na modelagem de peças, pelo método de elementos finitos e na simulação de forjamento.

O programa trabalha com três modelos de atrito, que podem ser adotados para simulação. Sendo:

- Modelo $1 \tau_{i}=\alpha_{f} K$

- Modelo $2 \tau_{i}=m K$

- Modelo $3 \tau_{i}=\mu \sigma_{f}$

Onde $\left(\alpha_{f}\right)$ é o coeficiente de atrito, definido pelo programa, para o modelo "viscoplastique", que leva em conta, a efetiva área de contato da superfície de interface entre o material, o lubrificante (caso exista) e a ferramenta, o que nos parece similar a condição da equação 8 , merecendo uma melhor investigação.

As equações 10 e 11 são as mesmas equações de número 4 e 2 já descritas neste trabalho, os modelos podem ser usados pelo programa, adotando-se na entrada de 
dados as palavras, "Tresca" e "Coulomb", respectivamente. Neste trabalho empregou-se o modelo "Coulomb".

As curvas de calibração foram obtidas, criando-se o modelo em 3 dimensões do anel no programa, com as dimensões e proporções dos anéis dos ensaios, considerando-se um material do banco de dados do programa e usando como similar, para fins de simulação (material WNr 1. 5120 e $\mathrm{WNr}$ 1.1128) e impondo-se ao programa um coeficiente de atrito, conforme a equação 11. Uma deformação na altura do anel foi criada, fazendo-se o processo de simulação da compressão do anel, com isso conseguiu-se simular a variação dos diâmetros internos pelo programa, este processo foi repetido variando-se os valores do coeficiente de atrito e da altura do anel após sua compressão, conforme valores abaixo:

Coeficientes de atrito usados para criar a tabela: $\mu=0 ; 0,03 ; 0,05 ; 0,07 ; 0,1 ; 0,15$; 0,$2 ; 0,3 ; 0,57$

Alturas impostas ao programa como deformação do anel: $\mathrm{h}=10 ; 8 ; 6 ; 5 ; 4 \mathrm{~mm}$, conforme ilustrado nas tabelas 3 e 4 . 
Tabela 3: Raio do anel medido pelo processo de simulação para o material DIN 38MnSiVS

\begin{tabular}{|c|c|c|c|c|c|c|}
\hline $\begin{array}{c}\text { Coef. } \\
\text { Atrito }\end{array}$ & \multicolumn{6}{|c|}{ Altura do anel } \\
\cline { 2 - 7 }$\mu$ & & 10,00 & 8,00 & 6,00 & 5,00 & 4,00 \\
\hline \multirow{2}{*}{$\mu=0$} & Raio int. & 7,50 & 8,27 & 9,30 & 10,02 & 11,00 \\
\cline { 2 - 7 } & \% Diam. & 0,00 & $-10,27$ & $-24,00$ & $-33,60$ & $-46,67$ \\
\hline \multirow{2}{*}{$\mu, 03$} & Raio int. & 7,50 & 8,10 & 8,64 & 8,86 & 8,98 \\
\cline { 2 - 7 } & \% Diam. & 0,00 & $-8,00$ & $-15,20$ & $-18,13$ & $-19,73$ \\
\hline \multirow{2}{*}{$\mu=0,05$} & Raio int. & 7,50 & 7,98 & 8,19 & 8,10 & 7,75 \\
\cline { 2 - 7 } & \% Diam. & 0,00 & $-6,40$ & $-9,20$ & $-8,00$ & $-3,33$ \\
\hline \multirow{2}{*}{$\mu=0,07$} & Raio int. & 7,50 & 7,85 & 7,72 & 7,35 & 6,76 \\
\cline { 2 - 7 } & \% Diam. & 0,00 & $-4,67$ & $-2,93$ & 2,00 & 9,87 \\
\hline \multirow{2}{*}{$\mu=0,1$} & Raio int. & 7,50 & 7,69 & 7,04 & 6,41 & 5,61 \\
\cline { 2 - 7 } & \% Diam. & 0,00 & $-2,00$ & 6,13 & 14,53 & 25,20 \\
\hline \multirow{2}{*}{$\mu=0,15$} & Raio int. & 7,50 & 7,34 & 6,29 & 5,48 & 4,28 \\
\cline { 2 - 7 } & \% Diam. & 0,00 & 2,13 & 16,33 & 26,93 & 42,93 \\
\hline \multirow{2}{*}{$\mu=0,2$} & Raio int. & 7,50 & 7,13 & 5,78 & 4,83 & 3,20 \\
\cline { 2 - 7 } & \% Diam. & 0,00 & 4,93 & 22,93 & 35,60 & 57,33 \\
\hline \multirow{2}{*}{$\mu=0,3$} & Raio int. & 7,50 & 6,82 & 5,13 & 3,88 & 1,32 \\
\cline { 2 - 7 } & \% Diam. & 0,00 & 9,07 & 31,60 & 48,26 & 82,40 \\
\hline \multirow{2}{*}{$\mu=0,577$} & Raio int. & 7,50 & 6,63 & 4,71 & 3,02 & 0,00 \\
\cline { 2 - 7 } & \% Diam. & 0,00 & 11,60 & 37,20 & 59,73 & 100,00 \\
\hline
\end{tabular}

Tabela 4: Raio do anel medido pelo processo de simulação para o material SAE 1548

\begin{tabular}{|c|c|c|c|c|c|c|}
\hline $\begin{array}{c}\text { Coef. } \\
\text { Atrito }\end{array}$ & \multicolumn{6}{|c|}{ Altura do anel } \\
\cline { 2 - 7 }$\mu=0$ & & 10,00 & 8,00 & 6,00 & 5,00 & 4,00 \\
\hline \multirow{2}{*}{$\mu=0,30$} & Raio int. & 7,50 & 8,28 & 9,30 & 10,01 & 10,98 \\
\cline { 2 - 7 } & \% Diam. & 0,00 & $-10,40$ & $-24,00$ & $-33,47$ & $-46,40$ \\
\hline \multirow{2}{*}{$\mu=0,03$} & Raio int. & 7,50 & 8,10 & 8,64 & 8,85 & 8,97 \\
\cline { 2 - 7 } & \% Diam. & 0,00 & $-8,00$ & $-15,20$ & $-18,00$ & $-19,60$ \\
\hline \multirow{2}{*}{$\mu=0,07$} & Raio int. & 7,50 & 7,98 & 8,19 & 8,09 & 7,74 \\
\cline { 2 - 7 } & \% Diam. & 0,00 & $-6,40$ & $-9,20$ & $-7,87$ & $-3,20$ \\
\hline \multirow{2}{*}{$\mu=0,1$} & Raio int. & 7,50 & 7,85 & 7,70 & 7,30 & 6,71 \\
\cline { 2 - 7 } & \% Diam. & 0,00 & $-4,67$ & $-2,67$ & 2,67 & 10,53 \\
\cline { 2 - 7 } & Raio int. & 7,50 & 7,69 & 7,04 & 6,42 & 5,60 \\
\hline \multirow{2}{*}{$\mu=0,15$} & Raio int. & 0,00 & $-2,53$ & 6,13 & 14,40 & 25,33 \\
\cline { 2 - 7 } & \% Diam. & 0,00 & 2,00 & 16,00 & 26,67 & 42,53 \\
\hline \multirow{2}{*}{$\mu=0,2$} & Raio int. & 7,50 & 7,14 & 5,79 & 4,85 & 3,22 \\
\cline { 2 - 7 } & \% Diam. & 0,00 & 4,80 & 22,80 & 35,33 & 57,07 \\
\hline \multirow{2}{*}{$\mu=0,3$} & Raio int. & 7,50 & 6,82 & 5,13 & 3,90 & 1,18 \\
\cline { 2 - 7 } & \% Diam. & 0,00 & 9,07 & 31,60 & 48,00 & 84,27 \\
\hline \multirow{2}{*}{$\mu=0,577$} & Raio int. & 7,50 & 6,63 & 4,69 & 3,01 & 0,00 \\
\cline { 2 - 7 } & \% Diam. & 0,00 & 11,60 & 37,47 & 59,87 & 100,00 \\
\hline
\end{tabular}

A partir dos dados das tabelas 3 e 4, foram obtidas as curvas de calibração indicadas nas Figura 20 e 21. 


\section{Curvas de Calibração}

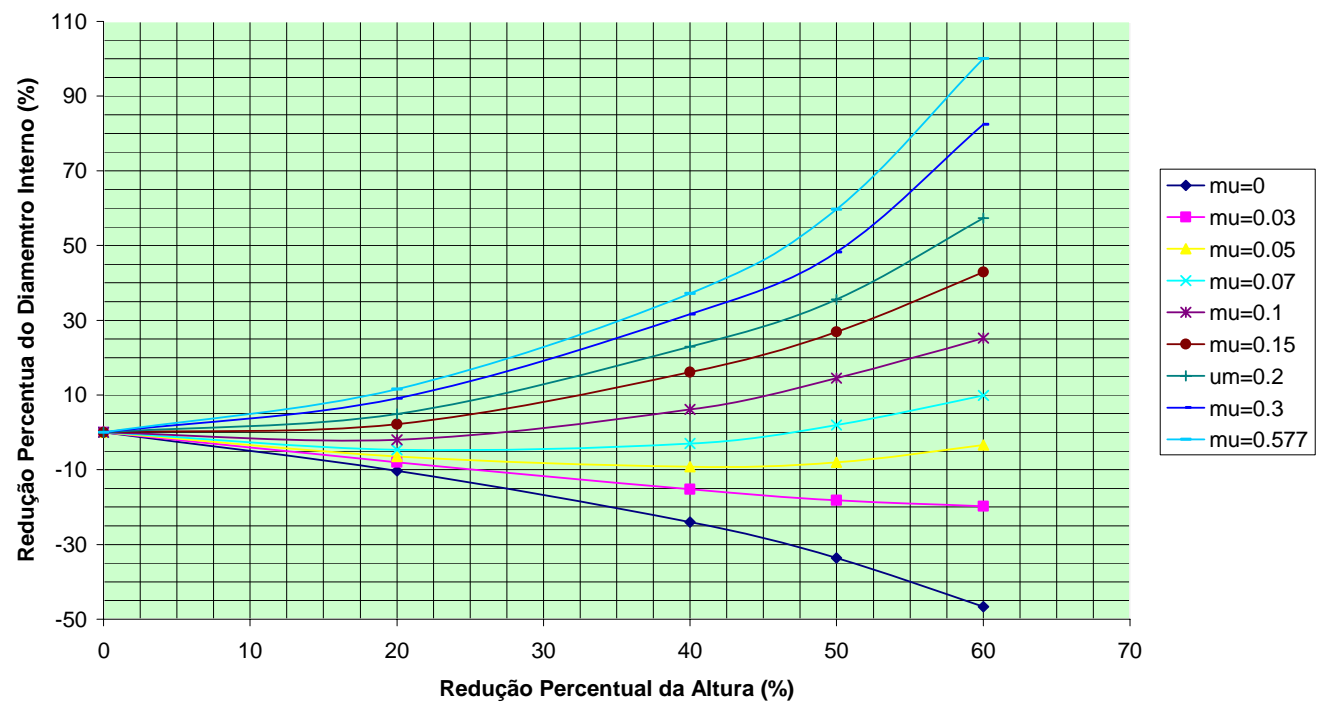

Figura 20: Curva de calibração gerada com diâmetros obtidos pelo programa de simulação FORGE 3 (2004), para o material DIN 38MnSiVS.

\section{Curvas de Calibração}

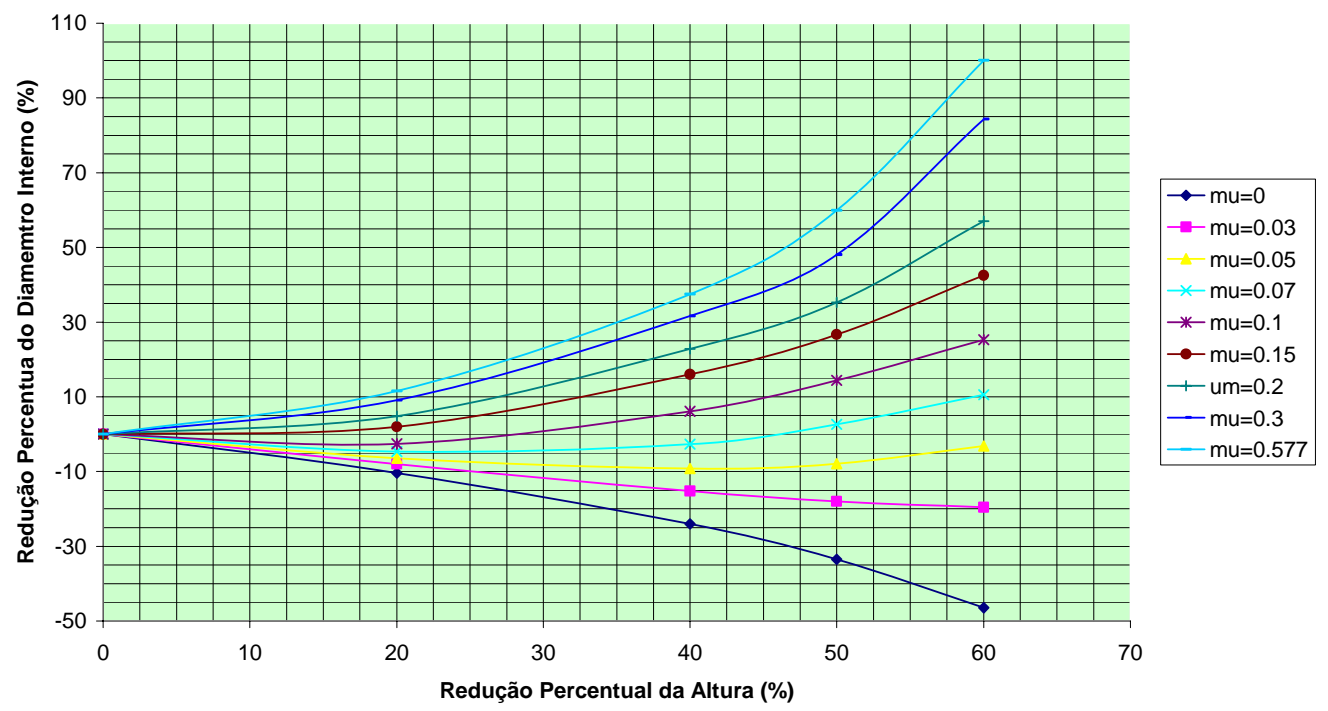

Figura 21: Curva de calibração gerada com diâmetros obtidos pelo programa de simulação FORGE 3 (2004), para o material SAE 1548

Pode ser visto, pelas tabelas e gráficos, que há uma concordância das curvas. Assim foi possível ser usada apenas uma curva para determinação do coeficiente de atrito 
das peças ensaiadas no LdTM da UFRGS, obtendo-se assim os valores da tabela 6 .

\subsubsection{Procedimento para Simulação do Experimento}

O processo de simulação foi feito usando-se o programa FORGE 3 (2004) de propriedade da empresa ThyssenKrupp Metalúrgica Campo Limpo, tomando-se como base, os valores das alturas dos anéis, medidos após os experimentos, e adotando-se os valores dos coeficientes de atrito, obtidos através da curva de calibração da figura 20 .

Foi feita a simulação de cada experimento realizado, considerando-se suas mesmas condições de:

- Coeficiente de atrito (adotado modelo de atrito da equação 11).

- Temperatura da peça.

- Velocidade da prensa.

- Temperatura de matriz.

Assim, para cada simulação, foi possível ser feita a medida do diâmetro interno do anel na altura pré-determinada.

No processo de simulação, foram usados os materiais da base de dados do programa, por serem, normalmente, usados como materiais equivalentes aos materiais usados nos experimentos. Este procedimento foi adotado, pois o banco de dados do programa já possui todas as características mecânicas destes materiais. Os materiais usados foram:

- WNr 1. 5120 como equivalente ao DIN 38Mn SiVS 5 .

- WNr 1.1128 como equivalente ao SAE 1548. 


\section{RESULTADOS}

\subsection{Resultados dos Experimentos}

Os resultados, das dimensões dos diâmetros internos e alturas dos anéis, obtidos após a realização dos experimentos, estão indicados na tabela 5.

Tabela 5: Tabela com resultados dos diâmetros e alturas dos anéis obtidos nos experimentos

\begin{tabular}{|c|c|c|c|c|c|c|c|c|c|}
\hline Ensaio & Amostra & $\mathrm{V}(\mathbf{m m} / \mathbf{s})$ & Temp. $\left({ }^{\circ} \mathrm{C}\right)$ & Revest. & Material & \begin{tabular}{|c|} 
Diam int.d \\
$(\mathrm{mm})$
\end{tabular} & h (mm) & \begin{tabular}{|c|} 
Red. Diam \\
int.d (\%)
\end{tabular} & $\begin{array}{c}\text { Red de h } \\
(\%)\end{array}$ \\
\hline 1 & 1 & 2 & 800 & Polido & 1548 & 14,8 & 7,0 & 1 & 30 \\
\hline 2 & 7 & 15 & 800 & Polido & 1548 & 14,7 & 7,3 & 2 & 27 \\
\hline 3 & 14 & 2 & 1200 & Polido & 1548 & 11,0 & 6,2 & 27 & 38 \\
\hline 4 & 11 & 15 & 1200 & Polido & 1548 & 9,3 & 4,2 & 38 & 58 \\
\hline 5 & 19 & 2 & 800 & Revestido & 1548 & 13,9 & 7,0 & 7 & 30 \\
\hline 6 & 18 & 15 & 800 & Revestido & 1548 & 12,6 & 6,0 & 16 & 40 \\
\hline 7 & 22 & 2 & 1200 & Revestido & 1548 & 11,8 & 5,4 & 22 & 46 \\
\hline 8 & 26 & 15 & 1200 & Revestido & 1548 & 12,3 & 6,9 & 18 & 31 \\
\hline 9 & 8 & 2 & 800 & Polido & 38MnSiVS5 & 14,5 & 7,9 & 3 & 21 \\
\hline 10 & 5 & 15 & 800 & Polido & $38 \mathrm{MnSiVS5}$ & 14,0 & 6,0 & 7 & 40 \\
\hline 11 & 17 & 2 & 1200 & Polido & $38 \mathrm{MnSiVS5}$ & 11,8 & 5,5 & 21 & 45 \\
\hline 12 & 16 & 15 & 1200 & Polido & 38MnSiVS5 & 13,4 & 6,9 & 11 & 31 \\
\hline 13 & 21 & 2 & 800 & Revestido & $38 \mathrm{MnSiVS5}$ & 14,3 & 8,0 & 5 & 20 \\
\hline 14 & 20 & 15 & 800 & Revestido & $38 \mathrm{MnSiVS5}$ & 13,5 & 7,0 & 10 & 30 \\
\hline 15 & 30 & 2 & 1200 & Revestido & 38MnSiVS5 & 12,1 & 6,8 & 19 & 32 \\
\hline 16 & 27 & 15 & 1200 & Revestido & $38 \mathrm{MnSiVS5}$ & 12,6 & 4,5 & 16 & 55 \\
\hline
\end{tabular}

\subsection{Resultados dos Coeficientes de Atrito $(\mu)$}

Com os resultados da tabela 5, foram obtidos os valores dos coeficientes de atrito para cada experimento, usando-se a curva de calibração da figura 20. Estes valores foram lançados na tabela 6 . 
Tabela 6: Valores dos coeficientes de atrito $(\mu)$ para cada experimento

\begin{tabular}{|c|c|c|c|c|c|c|c|c|c|c|}
\hline Ensaio & Amostra & $\mathbf{V}(\mathbf{m m} / \mathbf{s})$ & Temp. $\left({ }^{\circ} \mathbf{C}\right)$ & Revest. & Material & $\begin{array}{c}\text { Diam int.d } \\
(\mathbf{m m})\end{array}$ & $\mathbf{h}(\mathbf{m m})$ & $\begin{array}{c}\text { Red. Diam } \\
\text { int.d }(\mathbf{\%})\end{array}$ & $\begin{array}{c}\text { Red de h } \\
(\mathbf{\%})\end{array}$ & $\begin{array}{c}\text { Coef atrito } \\
(\boldsymbol{\mu})\end{array}$ \\
\hline 1 & 1 & 2 & 800 & Polido & 1548 & 14,8 & 7,0 & 1 & 30 & 0,10 \\
\hline 2 & 7 & 15 & 800 & Polido & 1548 & 14,7 & 7,3 & 2 & 27 & 0,12 \\
\hline 3 & 14 & 2 & 1200 & Polido & 1548 & 11,0 & 6,2 & 27 & 38 & 0,26 \\
\hline 4 & 11 & 15 & 1200 & Polido & 1548 & 9,3 & 4,2 & 38 & 58 & 0,14 \\
\hline 5 & 19 & 2 & 800 & Revestido & 1548 & 13,9 & 7,0 & 7 & 30 & 0,13 \\
\hline 6 & 18 & 15 & 800 & Revestido & 1548 & 12,6 & 6,0 & 16 & 40 & 0,15 \\
\hline 7 & 22 & 2 & 1200 & Revestido & 1548 & 11,8 & 5,4 & 22 & 46 & 0,16 \\
\hline 8 & 26 & 15 & 1200 & Revestido & 1548 & 12,3 & 6,9 & 18 & 31 & 0,29 \\
\hline 9 & 8 & 2 & 800 & Polido & 38 MnSiVS5 & 14,5 & 7,9 & 3 & 21 & 0,16 \\
\hline 10 & 5 & 15 & 800 & Polido & 38 MnSiVS5 & 14,0 & 6,0 & 7 & 40 & 0,11 \\
\hline 11 & 17 & 2 & 1200 & Polido & 38 MnSiVS5 & 11,8 & 5,5 & 21 & 45 & 0,16 \\
\hline 12 & 16 & 15 & 1200 & Polido & 38 MnSiVS5 & 13,4 & 6,9 & 11 & 31 & 0,18 \\
\hline 13 & 21 & 2 & 800 & Revestido & 38 MnSiVS5 & 14,3 & 8,0 & 5 & 20 & 0,20 \\
\hline 14 & 20 & 15 & 800 & Revestido & 38 MnSiVS5 & 13,5 & 7,0 & 10 & 30 & 0,17 \\
\hline 15 & 30 & 2 & 1200 & Revestido & 38 MnSiVS5 & 12,1 & 6,8 & 19 & 32 & 0,26 \\
\hline 16 & 27 & 15 & 1200 & Revestido & 38 MnSiVS5 & 12,6 & 4,5 & 16 & 55 & 0,09 \\
\hline
\end{tabular}

\subsection{Resultados da Simulação}

Fazendo-se a simulação dos experimentos, com o programa FORGE 3 (2004),

conforme descrito no item 4.2.4, foram obtidos os valores dos diâmetros internos dos

anéis, considerando-se as mesmas alturas obtidas no experimento, estes valores são

mostrados na tabela 7 .

Tabela 7: Diâmetro interno do anel obtido com a simulação de cada experimento

\begin{tabular}{|c|c|c|c|c|c|c|c|c|c|c|c|}
\hline Ensaio & Amostra & $\mathrm{V}(\mathrm{mm} / \mathrm{s})$ & Temp. $\left({ }^{\circ} \mathrm{C}\right)$ & Revest. & Material & $\begin{array}{c}\text { Diam int.d } \\
(\mathrm{mm})\end{array}$ & h (mm) & \begin{tabular}{|c|} 
Red. Diam \\
int.d (\%)
\end{tabular} & $\begin{array}{c}\text { Red de h } \\
(\%)\end{array}$ & \begin{tabular}{|c|} 
Coef atrito \\
$(\mu)$
\end{tabular} & \begin{tabular}{|c|} 
Diam int.d \\
simulado \\
\end{tabular} \\
\hline 1 & 1 & 2 & 800 & Polido & 1548 & 14,8 & 7,0 & 1 & 30 & 0,10 & 15,0 \\
\hline 2 & 7 & 15 & 800 & Polido & 1548 & 14,7 & 7,3 & 2 & 27 & 0,12 & 14,8 \\
\hline 3 & 14 & 2 & 1200 & Polido & 1548 & 11,0 & 6,2 & 27 & 38 & 0,26 & 10,0 \\
\hline 4 & 11 & 15 & 1200 & Polido & 1548 & 9,3 & 4,2 & 38 & 58 & 0,14 & 9,3 \\
\hline 5 & 19 & 2 & 800 & Revestido & 1548 & 13,9 & 7,0 & 7 & 30 & 0,13 & 14,3 \\
\hline 6 & 18 & 15 & 800 & Revestido & 1548 & 12,6 & 6,0 & 16 & 40 & 0,15 & 13,4 \\
\hline 7 & 22 & 2 & 1200 & Revestido & 1548 & 11,8 & 5,4 & 22 & 46 & 0,16 & 10,7 \\
\hline 8 & 26 & 15 & 1200 & Revestido & 1548 & 12,3 & 6,9 & 18 & 31 & 0,29 & 11,9 \\
\hline 9 & 8 & 2 & 800 & Polido & 38MnSiVS5 & 14,5 & 7,9 & 3 & 21 & 0,16 & 14,4 \\
\hline 10 & 5 & 15 & 800 & Polido & 38MnSiVS5 & 14,0 & 6,0 & 7 & 40 & 0,11 & 14,0 \\
\hline 11 & 17 & 2 & 1200 & Polido & 38MnSiVS5 & 11,8 & 5,5 & 21 & 45 & 0,16 & 10,6 \\
\hline 12 & 16 & 15 & 1200 & Polido & 38MnSiVS5 & 13,4 & 6,9 & 11 & 31 & 0,18 & 13,0 \\
\hline 13 & 21 & 2 & 800 & Revestido & 38MnSiVS5 & 14,3 & 8,0 & 5 & 20 & 0,20 & 13,9 \\
\hline 14 & 20 & 15 & 800 & Revestido & 38MnSiVS5 & 13,5 & 7,0 & 10 & 30 & 0,17 & 13,8 \\
\hline 15 & 30 & 2 & 1200 & Revestido & 38MnSiVS5 & 12,1 & 6,8 & 19 & 32 & 0,26 & 11,2 \\
\hline 16 & 27 & 15 & 1200 & Revestido & 38MnSiVS5 & 12,6 & 4,5 & 16 & 55 & 0,09 & 13,0 \\
\hline
\end{tabular}




\subsection{Comparação de Resultados}

Comparando-se os resultados obtidos da medida do diâmetro interno dos anéis nos experimentos, com a medida do diâmetro interno do anel obtido na simulação, obteve-se a tabela 8 .

Tabela 8: Comparação dos diâmetros internos obtidos nos ensaios e nas simulações feitas com o programa FORGE 3 (2004)

\begin{tabular}{|c|c|c|c|c|}
\hline Ensaio & Amostra & $\begin{array}{c}\text { Diam int.d } \\
\text { (mm) }\end{array}$ & $\begin{array}{c}\text { Diam int.d } \\
\text { simulado } \\
\text { (mm) }\end{array}$ & \% Erro \\
\hline 1 & 1 & $\mathbf{1 4 , 8}$ & $\mathbf{1 5 , 0}$ & 1,35 \\
\hline 2 & 7 & $\mathbf{1 4 , 7}$ & $\mathbf{1 4 , 8}$ & 0,68 \\
\hline 3 & 14 & $\mathbf{1 1 , 0}$ & $\mathbf{1 0 , 0}$ & 9,09 \\
\hline 4 & 11 & $\mathbf{9 , 3}$ & $\mathbf{9 , 3}$ & 0,00 \\
\hline 5 & 19 & $\mathbf{1 3 , 9}$ & $\mathbf{1 4 , 3}$ & 2,88 \\
\hline 6 & 18 & $\mathbf{1 2 , 6}$ & $\mathbf{1 3 , 4}$ & 6,35 \\
\hline 7 & 22 & $\mathbf{1 1 , 8}$ & $\mathbf{1 0 , 7}$ & 8,94 \\
\hline 8 & 26 & $\mathbf{1 2 , 3}$ & $\mathbf{1 1 , 9}$ & 3,25 \\
\hline 9 & 8 & $\mathbf{1 4 , 5}$ & $\mathbf{1 4 , 4}$ & 0,69 \\
\hline 10 & 5 & $\mathbf{1 4 , 0}$ & $\mathbf{1 4 , 0}$ & 0,00 \\
\hline 11 & 17 & $\mathbf{1 1 , 8}$ & $\mathbf{1 0 , 6}$ & 10,17 \\
\hline 12 & 16 & $\mathbf{1 3 , 4}$ & $\mathbf{1 3 , 0}$ & 2,99 \\
\hline 13 & 21 & $\mathbf{1 4 , 3}$ & $\mathbf{1 3 , 9}$ & 2,80 \\
\hline 14 & 20 & $\mathbf{1 3 , 5}$ & $\mathbf{1 3 , 8}$ & 2,22 \\
\hline 15 & 30 & $\mathbf{1 2 , 1}$ & $\mathbf{1 1 , 2}$ & 7,44 \\
\hline 16 & 27 & $\mathbf{1 2 , 6}$ & $\mathbf{1 3 , 0}$ & 3,17 \\
\hline
\end{tabular}

\subsection{Resultados Gráficos da Simulação}

Com o processo de simulação, através do programa FORGE 3 (2004), foi possível obterem-se curvas, mostrando algumas particularidades do ensaio do anel, como exemplo são colocadas curvas de simulação feitas considerando-se uma amostra forjada a $800^{\circ} \mathrm{C}$ e uma amostra forjada a $1200^{\circ} \mathrm{C}$. 


\subsubsection{Vetores Velocidade de Escoamento de Material}

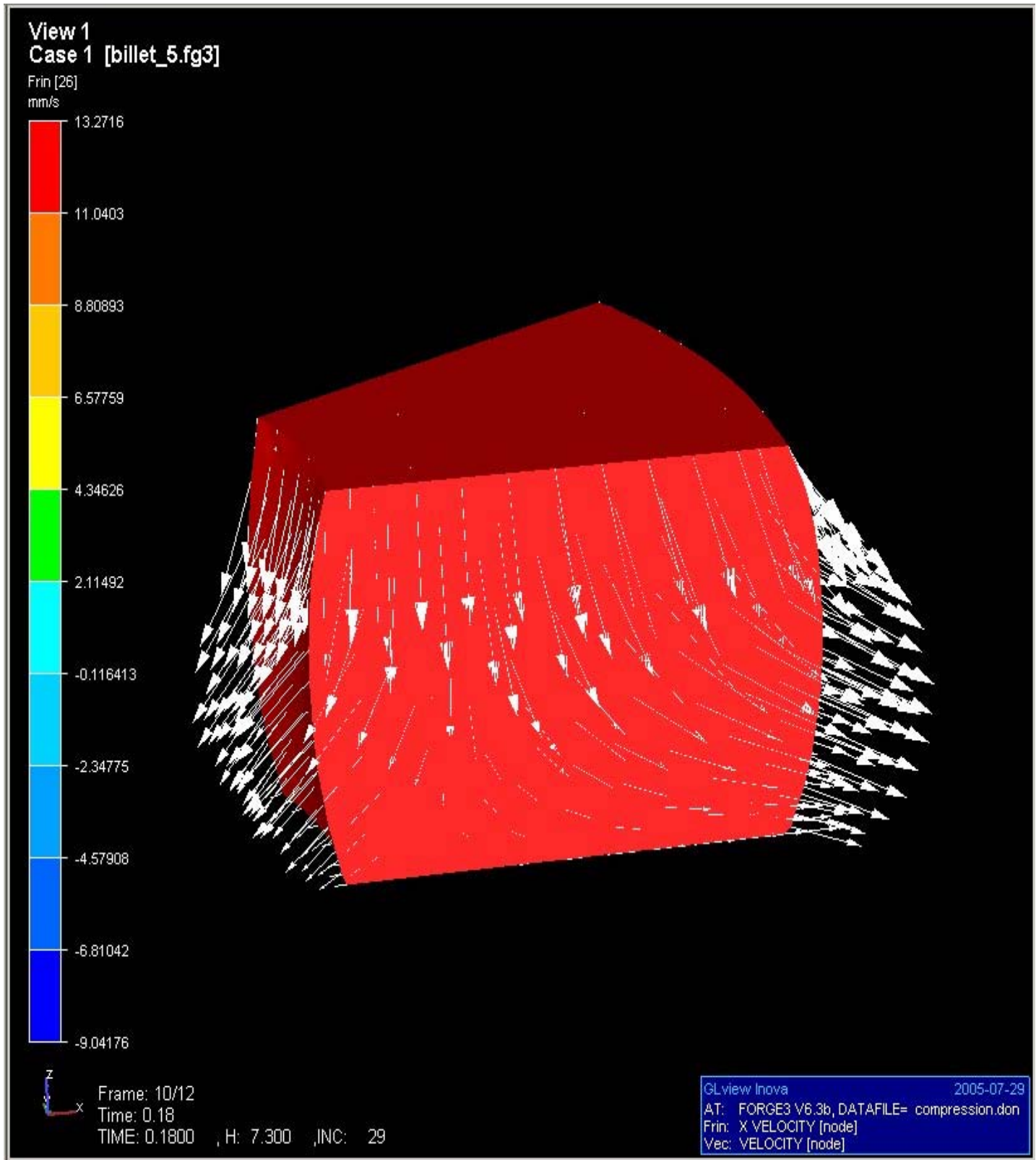

Figura 22: Vetores velocidade de escoamento de material na simulação do ensaio de compressão do anel, obtido através do programa FORGE 3 (2004), amostra 7

Nas figuras 22 e 23, pode-se constatar o aparecimento da superfície neutra para as amostra 7 e 11 , ensaios realizados a $800^{\circ} \mathrm{C}$ e $1200^{\circ} \mathrm{C}$, respectivamente. 


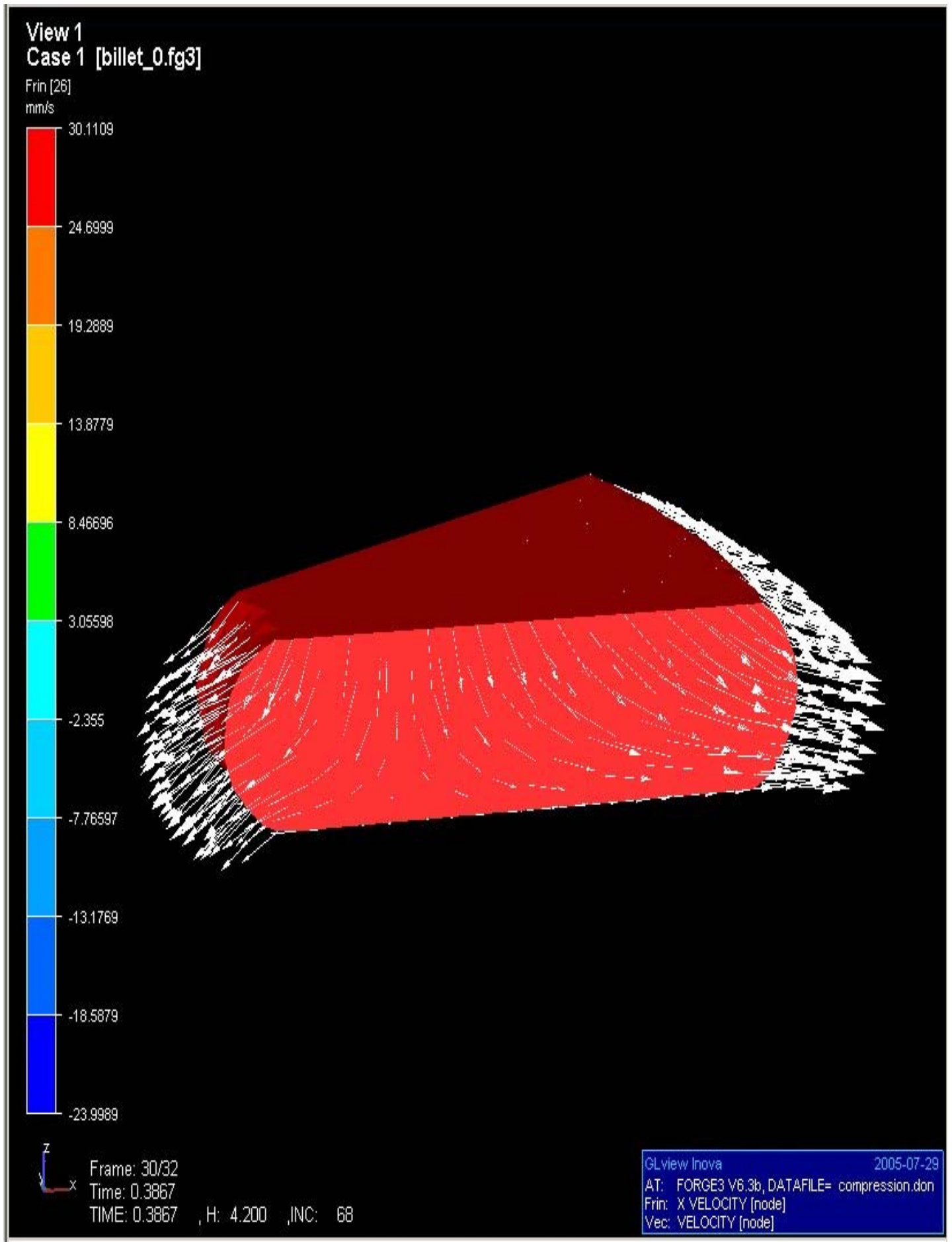

Figura 23: Vetores velocidade de escoamento de material na simulação do ensaio de compressão do anel, obtido através do programa FORGE 3 (2004), amostra 11 


\subsubsection{Velocidade de Escoamento do Material}

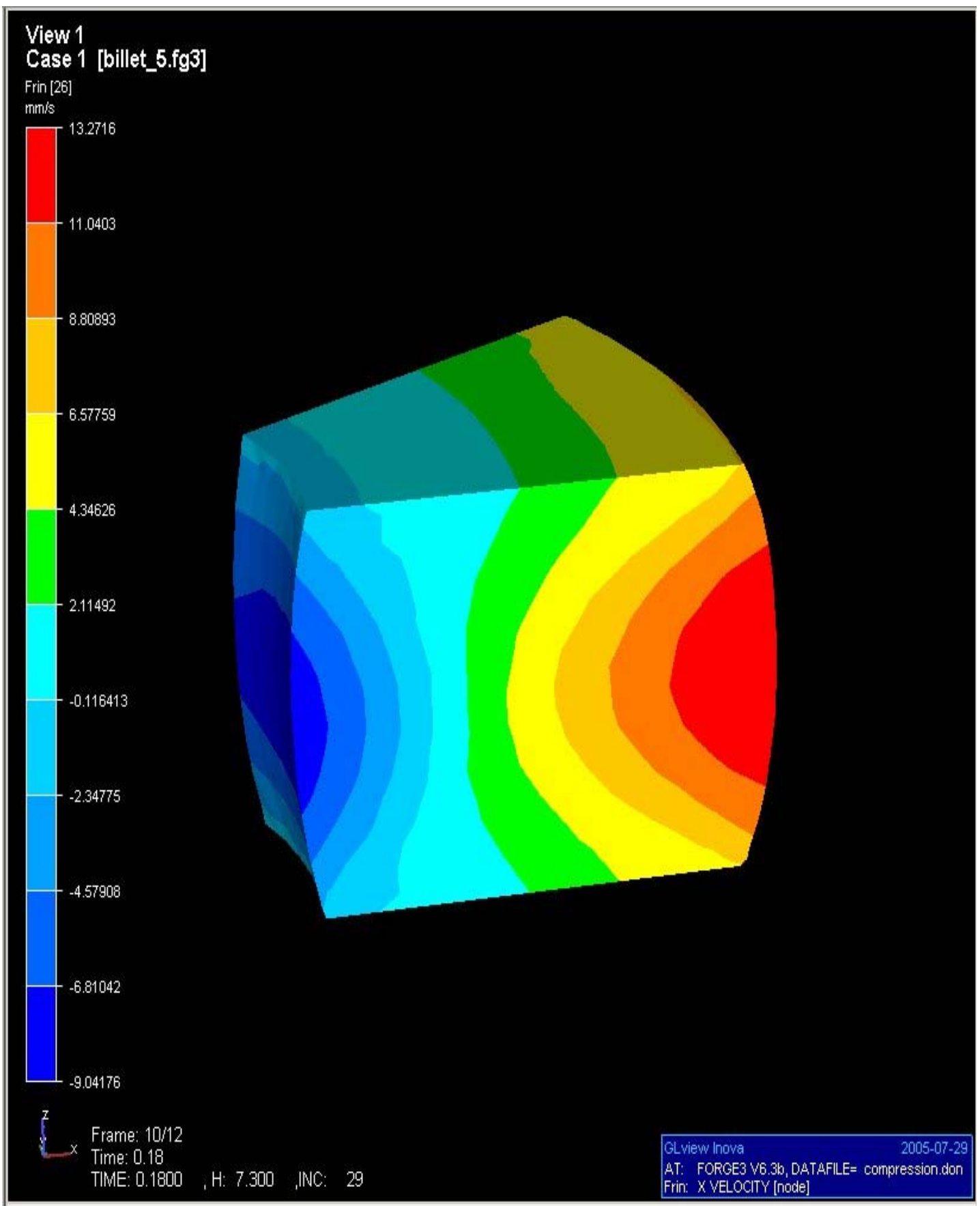

Figura 24: Velocidade de escoamento do material na simulação do ensaio de compressão do anel, obtido através do programa FORGE 3 (2004), amostra 7. 


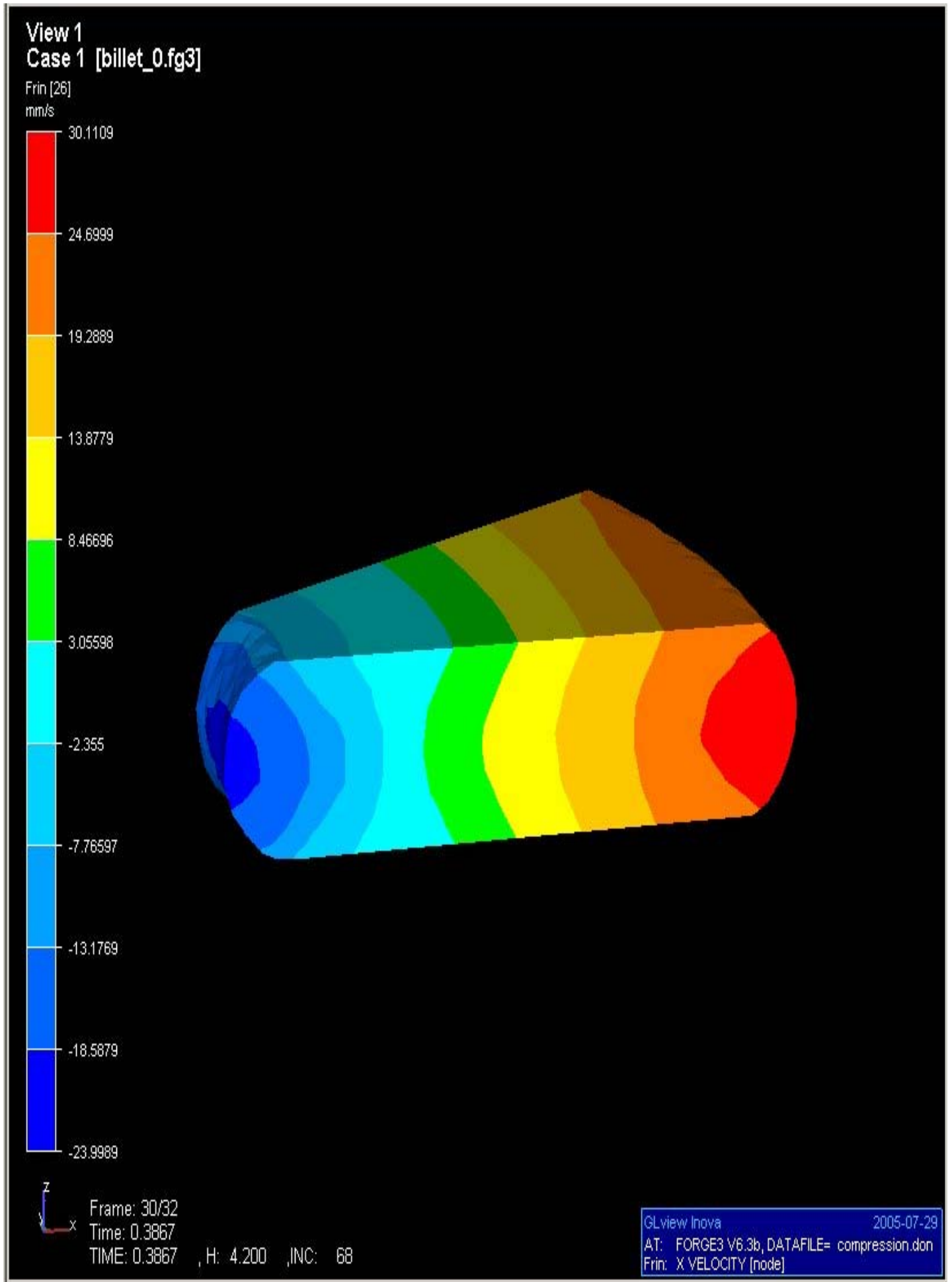

Figura 25: Velocidade de escoamento do material na simulação do ensaio de compressão do anel, obtido através do programa FORGE 3 (2004), amostra 11. 


\subsubsection{Temperatura do Anel}

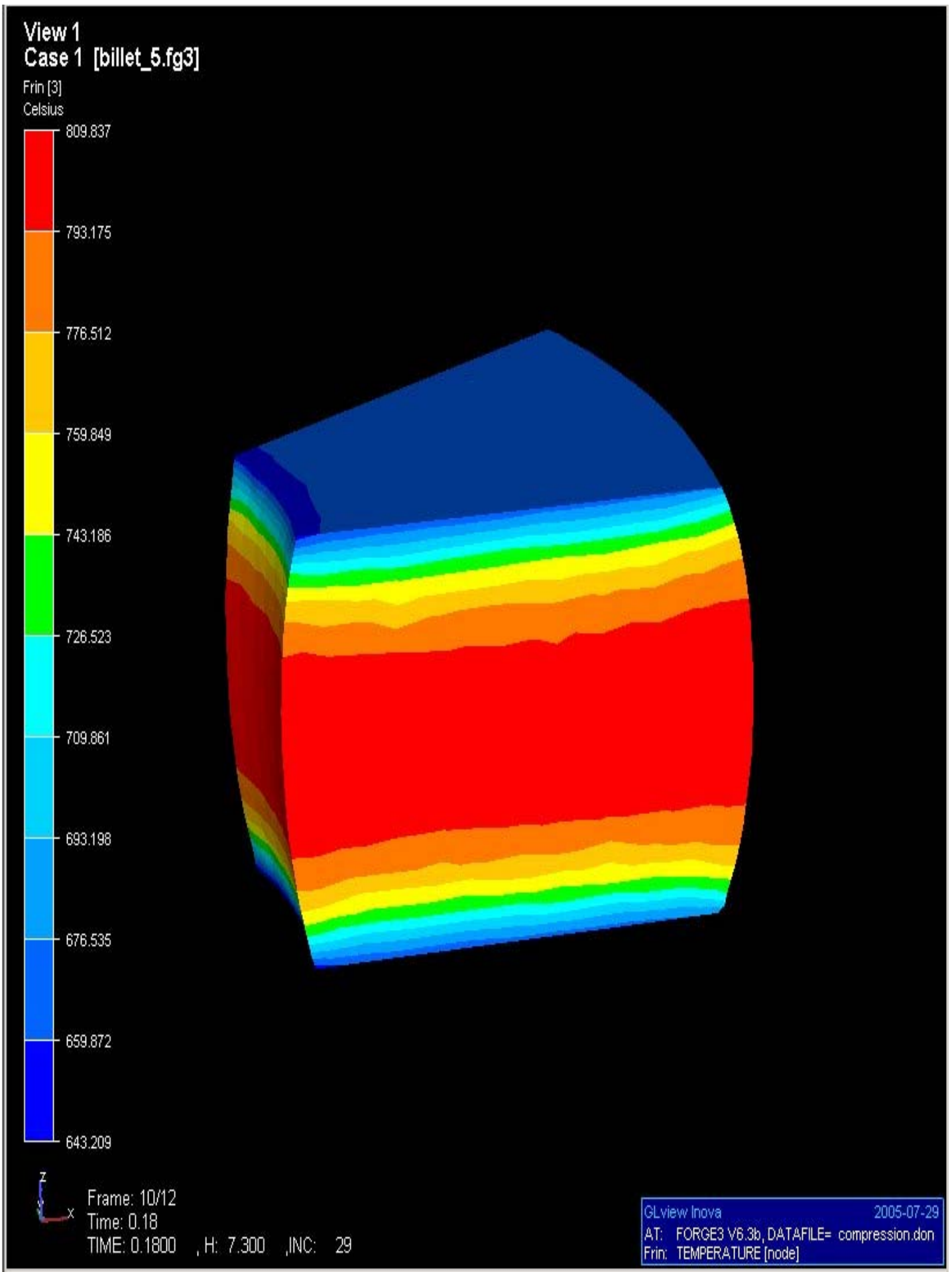

Figura 26: Perfil de temperatura do anel durante simulação do ensaio de compressão do anel, obtido através do programa FORGE 3 (2004), amostra 7 ensaio a $800^{\circ} \mathrm{C}$ 


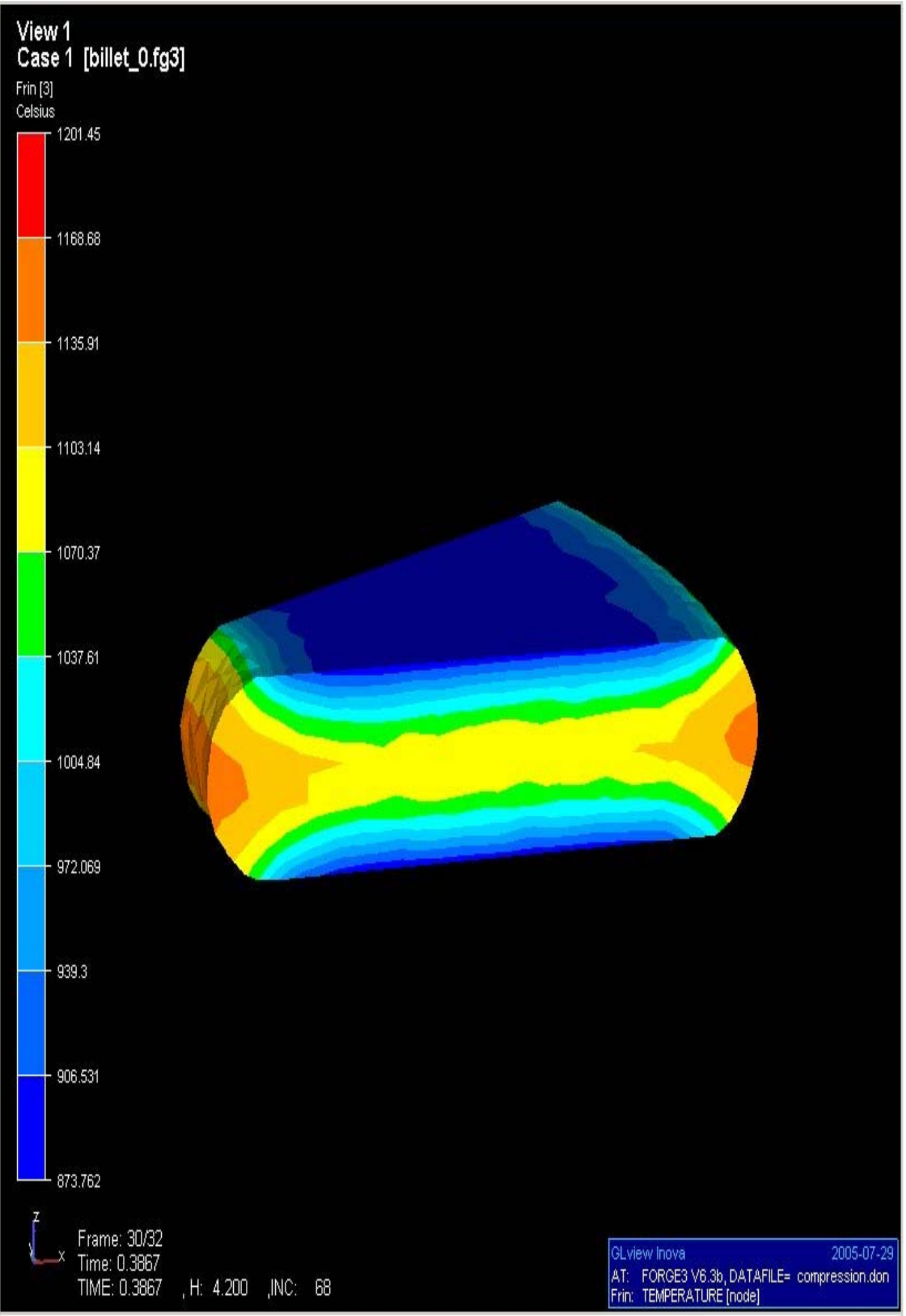

Figura 27: Perfil de temperatura do anel durante simulação do ensaio de compressão do anel, obtido através do programa FORGE 3 (2004), amostra 11 ensaio a $1200^{\circ} \mathrm{C}$ 
Nas figuras 26 e 27, pode-se constatar o resfriamento do anel, na região de contato com as matrizes, que foram consideras na simulação, à temperatura de $250^{\circ} \mathrm{C}$.

\subsection{Resultados Estatísticos dos Experimentos}

Os resultados dos experimentos, foram lançados no programa MINITAB (2000), de propriedade da empresa ThyssenKrupp Metalúrgica Campo Limpo, e através deste foram gerados gráficos de tendências dos experimentos e a sua confiabilidade.

Como resultados temos os gráficos das figuras 28 e 29 .

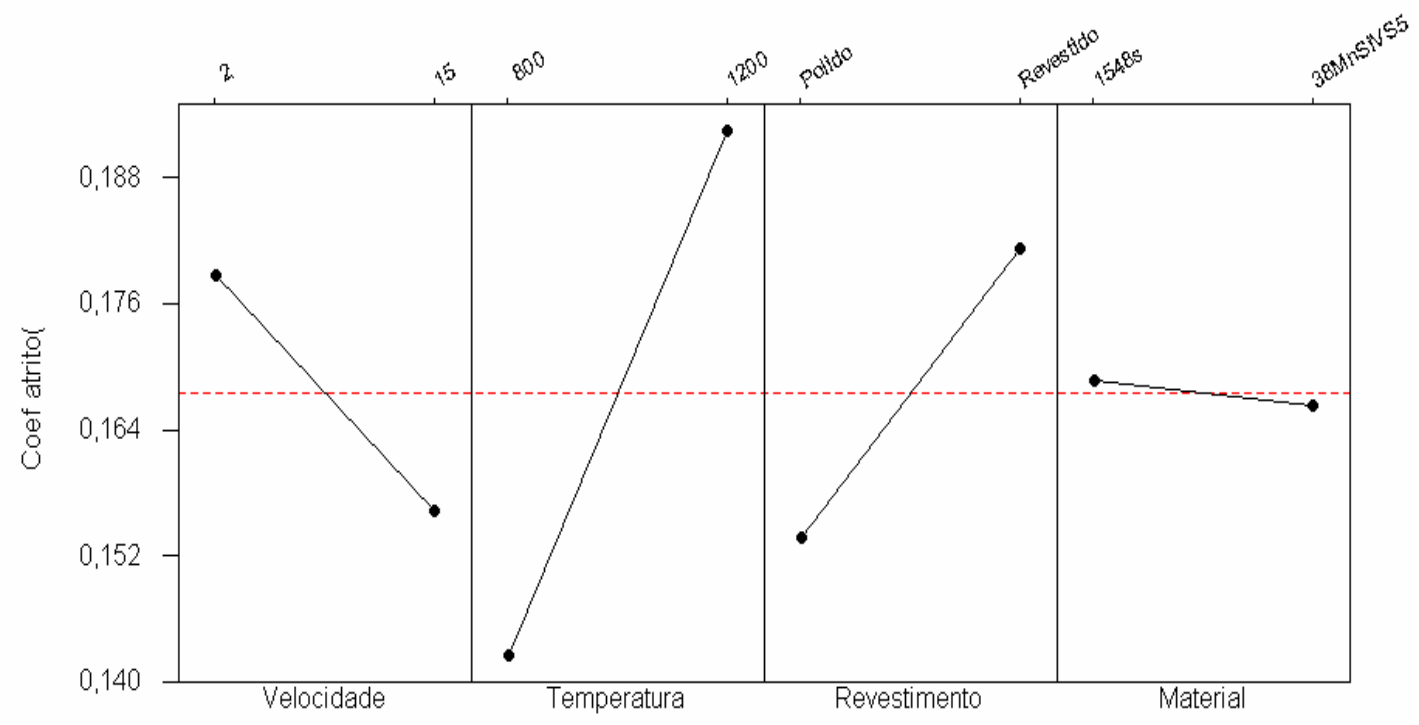

Figura 28: Efeito das variáveis do processo de forjamento a quente no coeficiente de atrito, obtido com programa MINITAB (2000)

No gráfico da figura 28 , pode ser visto a tendência de variação do coeficiente de atrito $\mu$, em relação a cada uma das variáveis de forjamento adotadas no item 4.2.1 deste trabalho. 
(response is Coef atr, Alpha $=, 05$ )

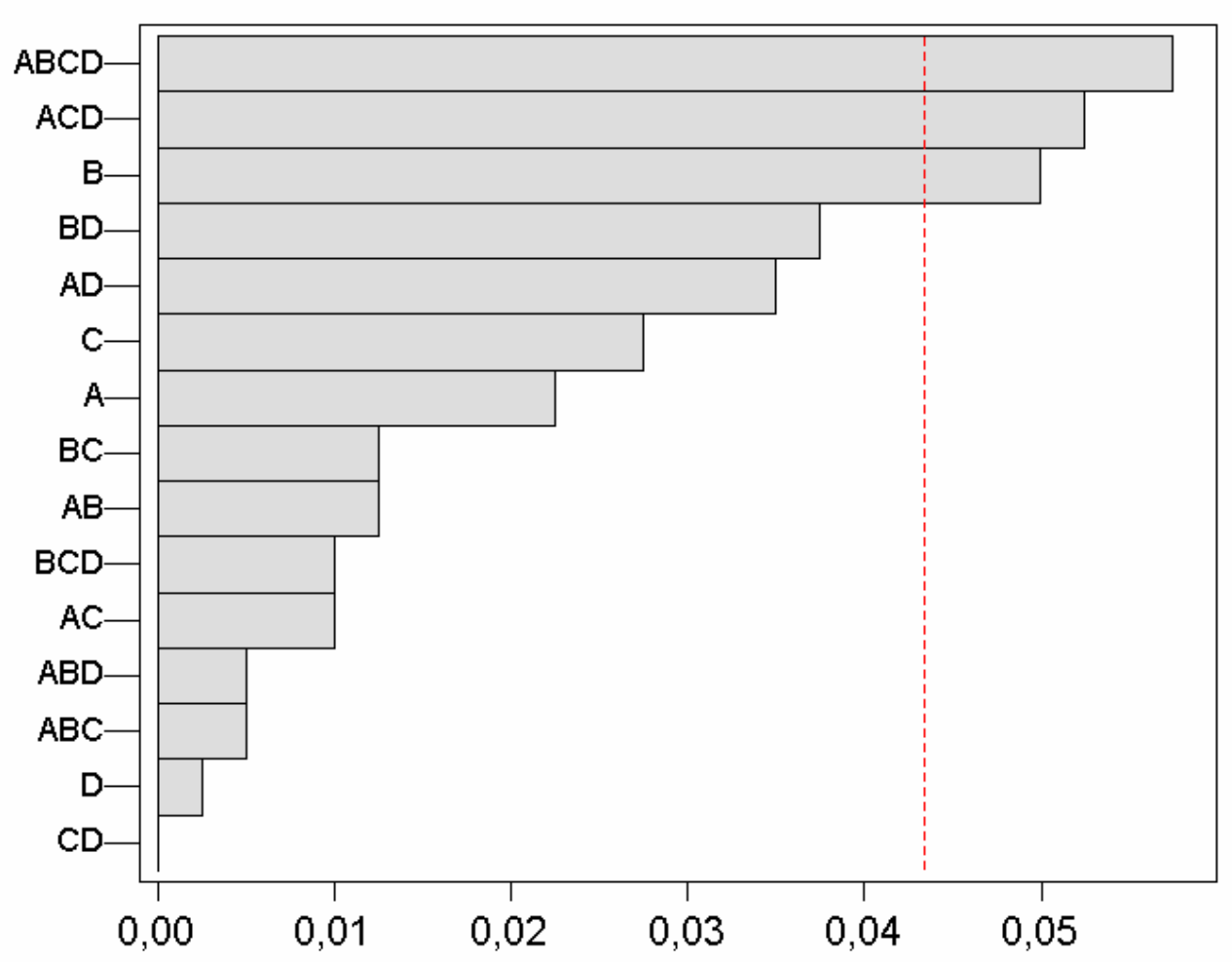

A: Velocida

B: Temperat

C: Revestim

D: Material

Figura 29: Gráfico com a influência das variáveis de processo de forjamento a quente no coeficiente de atrito para confiabilidade $95 \%$.

Este gráfico mostra as combinações das variáveis do processo de forjamento a quente e a influência, que uma variável isolada ou a combinação de duas ou mais variáveis possuem no coeficiente de atrito.

Foram feitas, também, as combinações possíveis das variáveis de forjamento e calculado os valores das médias, variância e desvio padrão dos coeficientes de atrito para cada combinação, os resultados são mostrados nas tabelas 9 e 10 . 
Tabela 9: Tabela com médias e desvios das combinações dos experimentos

\begin{tabular}{|c|c|c|c|c|}
\hline Item & Combinação & Média & Variância & Desvio Padrão \\
\hline 1.1 & $\mathrm{~T}=800^{\circ} \mathrm{C}$ & 0,14 & 0,0011 & 0,034 \\
\hline 1.2 & $\mathrm{~T}=1200^{\circ} \mathrm{C}$ & 0,19 & 0,0049 & 0,070 \\
\hline 1.3 & $\mathrm{~T}=800^{\circ} \mathrm{C}$ e material 1548 & 0,13 & 0,0004 & 0,020 \\
\hline 1.4 & $\mathrm{~T}=1200^{\circ} \mathrm{C}$ e material 1548 & 0,21 & 0,0054 & 0,074 \\
\hline 1.5 & $\mathrm{~T}=800^{\circ} \mathrm{C}$ e material $38 \mathrm{MnSiVS5}$ & 0,16 & 0,0014 & 0,037 \\
\hline 1.6 & $\mathrm{~T}=1200^{\circ} \mathrm{C}$ e material $38 \mathrm{MnSiVS} 5$ & 0,17 & 0,0049 & 0,070 \\
\hline 1.7 & $\mathrm{~T}=800^{\circ} \mathrm{C}$ e velocidade $=2 \mathrm{~mm} / \mathrm{s}$ & 0,15 & 0,0018 & 0,043 \\
\hline 1.8 & $\mathrm{~T}=800^{\circ} \mathrm{C}$ e velocidade $=15 \mathrm{~mm} / \mathrm{s}$ & 0,14 & 0,0008 & 0,028 \\
\hline 1.9 & $\mathrm{~T}=1200^{\circ} \mathrm{C}$ e velocidade $=2 \mathrm{~mm} / \mathrm{s}$ & 0,21 & 0,0033 & 0,058 \\
\hline 1.10 & $\mathrm{~T}=1200^{\circ} \mathrm{C}$ e velocidade $=15 \mathrm{~mm} / \mathrm{s}$ & 0,18 & 0,0072 & 0,085 \\
\hline 1.11 & $\mathrm{~T}=800^{\circ} \mathrm{C}$ e matriz polida & 0,12 & 0,0007 & 0,026 \\
\hline 1.12 & $\mathrm{~T}=1200^{\circ} \mathrm{C}$ e matriz polida & 0,19 & 0,0028 & 0,053 \\
\hline 1.13 & $\mathrm{~T}=800^{\circ} \mathrm{C}$ e matriz revestida & 0,16 & 0,0009 & 0,023 \\
\hline 1.14 & $\mathrm{~T}=1200^{\circ} \mathrm{C}$ e matriz revestida & 0,20 & 0,0085 & 0,092 \\
\hline 1.15 & $\begin{array}{l}\mathrm{T}=800^{\circ} \mathrm{C} \text { e velocidade }=2 \mathrm{~mm} / \mathrm{s} \text { e matriz } \\
\text { polida }\end{array}$ & 0,13 & 0,0018 & 0,042 \\
\hline 1.16 & $\begin{array}{l}\mathrm{T}=800^{\circ} \mathrm{C} \text { e velocidade }=15 \mathrm{~mm} / \mathrm{s} \text { e matriz } \\
\text { polida }\end{array}$ & 0,12 & 0,0001 & 0,010 \\
\hline 1.17 & $\begin{array}{l}\mathrm{T}=1200^{\circ} \mathrm{C} \text { e velocidade }=2 \mathrm{~mm} / \mathrm{s} \text { e matriz } \\
\text { polida }\end{array}$ & 0,21 & 0,0050 & 0,071 \\
\hline 1.18 & $\begin{array}{l}\mathrm{T}=1200^{\circ} \mathrm{C} \text { e velocidade }=15 \mathrm{~mm} / \mathrm{s} \text { e matriz } \\
\text { polida }\end{array}$ & 0,16 & 0,0080 & 0,028 \\
\hline 1.19 & $\begin{array}{l}\mathrm{T}=800^{\circ} \mathrm{C} \text { e velocidade }=2 \mathrm{~mm} / \mathrm{s} \text { e matriz } \\
\text { revestida }\end{array}$ & 0,17 & 0,0025 & 0,050 \\
\hline 1.20 & $\begin{array}{l}\mathrm{T}=800^{\circ} \mathrm{C} \text { e velocidade }=15 \mathrm{~mm} / \mathrm{s} \text { e matriz } \\
\text { revestida }\end{array}$ & 0,16 & 0,0002 & 0,014 \\
\hline 1.21 & $\begin{array}{l}\mathrm{T}=1200^{\circ} \mathrm{C} \text { e velocidade }=2 \mathrm{~mm} / \mathrm{s} \text { e matriz } \\
\text { revestida }\end{array}$ & 0,21 & 0,0050 & 0,071 \\
\hline 1.22 & $\begin{array}{l}\mathrm{T}=1200^{\circ} \mathrm{C} \text { e velocidade }=15 \mathrm{~mm} / \mathrm{s} \text { e matriz } \\
\text { revestida }\end{array}$ & 0,19 & 0,0200 & 0,140 \\
\hline 1.23 & $\begin{array}{l}\mathrm{T}=800^{\circ} \mathrm{C} \text { e velocidade }=2 \mathrm{~mm} / \mathrm{s} \text { e material } \\
1548\end{array}$ & 0,12 & 0,0005 & 0,021 \\
\hline 1.24 & $\begin{array}{l}\mathrm{T}=800^{\circ} \mathrm{C} \text { e velocidade }=15 \mathrm{~mm} / \mathrm{s} \text { e material } \\
1548\end{array}$ & 0,14 & 0,0005 & 0,021 \\
\hline 1.25 & $\begin{array}{l}\mathrm{T}=1200^{\circ} \mathrm{C} \text { e velocidade }=2 \mathrm{~mm} / \mathrm{s} \text { e material } \\
1548\end{array}$ & 0,21 & 0,0050 & 0,071 \\
\hline 1.26 & $\begin{array}{l}\mathrm{T}=1200^{\circ} \mathrm{C} \text { e velocidade }=15 \mathrm{~mm} / \mathrm{s} \mathrm{e} \\
\text { material } 1548\end{array}$ & 0,22 & 0,0112 & 0,106 \\
\hline 1.27 & $\begin{array}{l}\mathrm{T}=800^{\circ} \mathrm{C} \text { e velocidade }=2 \mathrm{~mm} / \mathrm{s} \text { e material } \\
38 \mathrm{MnSiVS} 5\end{array}$ & 0,18 & 0,0008 & 0,028 \\
\hline 1.28 & $\begin{array}{l}\mathrm{T}=800^{\circ} \mathrm{C} \text { e velocidade }=15 \mathrm{~mm} / \mathrm{s} \text { e material } \\
38 \mathrm{MnSiVS} 5\end{array}$ & 0,14 & 0,0018 & 0,042 \\
\hline 1.29 & $\begin{array}{l}\mathrm{T}=1200^{\circ} \mathrm{C} \text { e velocidade }=2 \mathrm{~mm} / \mathrm{s} \text { e material } \\
38 \mathrm{MnSiVS} 5\end{array}$ & 0,21 & 0,0050 & 0,071 \\
\hline 1.30 & $\begin{array}{l}\mathrm{T}=1200^{\circ} \mathrm{C} \text { e velocidade }=15 \mathrm{~mm} / \mathrm{s} \mathrm{e} \\
\text { material } 38 \mathrm{MnSiVS} 5\end{array}$ & 0,14 & 0,0041 & 0,064 \\
\hline 1.31 & $\mathrm{~T}=800^{\circ} \mathrm{C}$ e material 1548 e matriz polida & 0,11 & 0,0002 & 0,014 \\
\hline
\end{tabular}


Tabela 10: Continuação da tabela 9 com médias e desvios dos experimentos

\begin{tabular}{|c|c|c|c|c|}
\hline Item & Combinação & Média & Variância & Desvio Padrão \\
\hline 1.32 & $\mathrm{~T}=1200^{\circ} \mathrm{C}$ e material 1548 e matriz polida & 0,20 & 0,0072 & 0,085 \\
\hline 1.33 & $\begin{array}{l}\mathrm{T}=800^{\circ} \mathrm{C} \text { e material } 1548 \text { e matriz } \\
\text { revestida }\end{array}$ & 0,14 & 0,0002 & 0,014 \\
\hline 1.34 & $\begin{array}{l}\mathrm{T}=1200^{\circ} \mathrm{C} \text { e material } 1548 \text { e matriz } \\
\text { revestida }\end{array}$ & 0,23 & 0,0085 & 0,092 \\
\hline 1.35 & $\begin{array}{l}\mathrm{T}=800^{\circ} \mathrm{C} \text { e material } 38 \mathrm{MnSiVS5} \text { e matriz } \\
\text { polida }\end{array}$ & 0,14 & 0,0013 & 0,035 \\
\hline 1.36 & $\begin{array}{l}\mathrm{T}=1200^{\circ} \mathrm{C} \text { e material } 38 \mathrm{MnSiVS5} \text { e matriz } \\
\text { polida }\end{array}$ & 0,17 & 0,0002 & 0,014 \\
\hline 1.37 & $\begin{array}{l}\mathrm{T}=800^{\circ} \mathrm{C} \text { e material } 38 \mathrm{MnSiVS} 5 \text { e matriz } \\
\text { revestida }\end{array}$ & 0,19 & 0,0005 & 0,021 \\
\hline 1.38 & $\begin{array}{l}\mathrm{T}=1200^{\circ} \mathrm{C} \text { e material } 38 \mathrm{MnSiVS5} \text { e matriz } \\
\text { revestida }\end{array}$ & 0,18 & 0,0144 & 0,120 \\
\hline 2.1 & Velocidade $2 \mathrm{~mm} / \mathrm{s}$ & 0,18 & 0,0033 & 0,038 \\
\hline 2.2 & Velocidade $15 \mathrm{~mm} / \mathrm{s}$ & 0,16 & 0,0038 & 0,062 \\
\hline 2.3 & Velocidade $2 \mathrm{~mm} / \mathrm{s}$ e material 1548 & 0,16 & 0,0048 & 0,069 \\
\hline 2.4 & Velocidade $15 \mathrm{~mm} / \mathrm{s}$ e material 1548 & 0,18 & 0,0060 & 0,078 \\
\hline 2.5 & Velocidade $2 \mathrm{~mm} / \mathrm{s}$ e material $38 \mathrm{MnSiVS} 5$ & 0,19 & 0,0023 & 0,048 \\
\hline 2.6 & $\begin{array}{l}\text { Velocidade } 15 \mathrm{~mm} / \mathrm{s} \text { e material } \\
38 \mathrm{MnSiVS} 5\end{array}$ & 0,14 & 0,0020 & 0,044 \\
\hline 2.7 & Velocidade $2 \mathrm{~mm} / \mathrm{s}$ e matriz polida & 0,17 & 0,0044 & 0,066 \\
\hline 2.8 & Velocidade $15 \mathrm{~mm} / \mathrm{s}$ e matriz polida & 0,14 & 0,0010 & 0,031 \\
\hline 2.9 & Velocidade $2 \mathrm{~mm} / \mathrm{s}$ e matriz revestida & 0,19 & 0,0032 & 0,056 \\
\hline 2.10 & Velocidade $15 \mathrm{~mm} / \mathrm{s}$ e matriz revestida & 0,18 & 0,0070 & 0,084 \\
\hline 2.11 & $\begin{array}{l}\text { Velocidade } 2 \mathrm{~mm} / \mathrm{s} \text { e matriz polida e } \\
\text { material } 1548\end{array}$ & 0,18 & 0,0130 & 0,113 \\
\hline 2.12 & $\begin{array}{l}\text { Velocidade } 15 \mathrm{~mm} / \mathrm{s} \text { e matriz polida } \mathrm{e} \\
\text { material } 1548\end{array}$ & 0,13 & 0,0002 & 0,014 \\
\hline 2.13 & $\begin{array}{l}\text { Velocidade } 2 \mathrm{~mm} / \mathrm{s} \text { e matriz revestida e } \\
\text { material } 1548\end{array}$ & 0,15 & 0,0005 & 0,021 \\
\hline 2.14 & $\begin{array}{l}\text { Velocidade } 15 \mathrm{~mm} / \mathrm{s} \text { e matriz revestida e } \\
\text { material } 1548\end{array}$ & 0,22 & 0,0198 & 0,100 \\
\hline 2.15 & $\begin{array}{l}\text { Velocidade } 2 \mathrm{~mm} / \mathrm{s} \text { e matriz polida e } \\
\text { material } 38 \mathrm{MnSiVS} 5\end{array}$ & 0,16 & 0,0000 & 0,000 \\
\hline 2.16 & $\begin{array}{l}\text { Velocidade } 15 \mathrm{~mm} / \mathrm{s} \text { e matriz polida e } \\
\text { material } 38 \mathrm{MnSiVS} 5\end{array}$ & 0,15 & 0,0025 & 0,050 \\
\hline 2.17 & $\begin{array}{l}\text { Velocidade } 2 \mathrm{~mm} / \mathrm{s} \text { e matriz revestida e } \\
\text { material } 38 \mathrm{MnSiVS} 5\end{array}$ & 0,23 & 0,0018 & 0,042 \\
\hline 2.18 & $\begin{array}{l}\text { Velocidade } 15 \mathrm{~mm} / \mathrm{s} \text { e matriz revestida e } \\
\text { material } 38 \mathrm{MnSiVS} 5\end{array}$ & 0,13 & 0,0032 & 0,057 \\
\hline 3.1 & Material 1548 & 0,17 & 0,0047 & 0,070 \\
\hline 3.2 & Material 38MnSiVS5 & 0,17 & 0,0027 & 0,052 \\
\hline 3.3 & Material 1548 e matriz polida & 0,16 & 0,0052 & 0,072 \\
\hline 3.4 & Material 1548 e matriz revestida & 0,18 & 0,0053 & 0,073 \\
\hline 3.5 & Material 38MnSiVS5 e matriz polida & 0,15 & 0,0009 & 0,023 \\
\hline 3.6 & Material 38MnSiVS5 e matriz revestida & 0,18 & 0,0050 & 0,071 \\
\hline 4.1 & Matriz polida & 0,15 & 0,0025 & 0,050 \\
\hline 4.2 & Matriz revestida & 0,18 & 0,0044 & 0,066 \\
\hline
\end{tabular}




\section{ANÁLISE DO EXPERIMENTO}

O experimento apresentou resultados satisfatórios, quanto à comparação dos diâmetros internos dos anéis ensaiados no laboratório da UFRGS e os resultados obtidos através do processo de simulação computacional realizado com o programa FORGE 3 (2004). Conforme mostrou-se na tabela 8.

Analisando-se as variáveis de processo e suas tendências, figura 28, em relação ao coeficiente de atrito, pode-se verificar, que o coeficiente de atrito apresentou uma tendência de elevação, com o aumento da temperatura, este fato, aparentemente, contraria o experimento realizado por Male e Cocroft (1964), conforme indicado na figura 8 , onde o coeficiente de atrito do aço carbono, tende a aumentar com o aumento de temperatura e tende a cair com temperaturas maiores de $750^{\circ} \mathrm{C}$, o que seria o caso do presente ensaio, se fossem consideradas as temperaturas de aquecimento empregadas. Entretanto, nota-se na figura 26 que durante o ensaio realizado a temperatura de $800^{\circ} \mathrm{C}$, a temperatura verificada pelo processo de simulação, não ultrapassou os $800^{\circ} \mathrm{C}$ no centro e manteve-se abaixo desta temperatura na superfície em contato com a ferramenta, observa-se na figura 27 , que para o ensaio a temperatura de $1200^{\circ} \mathrm{C}$, as temperaturas ficaram entre $800^{\circ} \mathrm{C}$ e $1100^{\circ} \mathrm{C}$. Na primeira circunstância, o resultado obtido está de acordo com o de Male e Cockroft (1964), para a elevação de temperaturas abaixo de $800^{\circ} \mathrm{C}$, já na segunda circunstância, existe uma divergência dos resultados. Entretanto, devido as dificuldades de manutenção das temperaturas e do pequeno número de repetições, será necessário proceder a um maior número de repetições do ensaio. Embora não haja razão aparente para a variação (aumento ou diminuição) do coeficiente de atrito depender (qualitativamente) da temperatura, este fator deve ser analisado mais 
criteriosamente, uma vez que os ensaios de Male e Cockroft (1964), foram realizados sem lubrificação.

$\mathrm{Na}$ figura 29, pode-se verificar que o experimento não apresenta um resultado estatístico, que garanta uma confiabilidade de $95 \%$, pois o fator mais significativo é a combinação das quatro variáveis (temperatura, velocidade, material e revestimento), reforçando a necessidade de um maior número de repetições de cada experimento. Porém, pode-se ter uma visão qualitativa, verificando-se a influência no coeficiente de atrito de cada variável e a combinação delas.

Da análise da figura 29, observa-se que como fator isolado, a temperatura apresentou uma maior influência no coeficiente de atrito, seguida do revestimento, da velocidade e do tipo de material. Porém, quando é feita a análise da combinação de dois fatores, temperatura e material, aparecem como as variáveis mais significativas para o coeficiente de atrito, seguida pela combinação de velocidade e material. Confirmando, a importância da natureza do material, no coeficiente de atrito conforme Male e Cockoft (1964). Apesar de nos ítens 3.1 e 3.2 da tabela 10, mostrar que a média do coeficiente de atrito para o material SAE 1548 ser de 0,17 e a média do coeficiente de atrito para o material DIN 38MnSiVS5 ser de 0,17.

A velocidade da prensa atua diretamente na taxa de deformação do material, que também, representa um fator importante para o coeficiente de atrito, fato que, foi comprovado nos ensaios de Wang e Lenard (1992), segundo indicados na figura 10.

O tipo de material não foi um fator significativo no experimento. Este fato, também, foi comprovado na obtenção das curvas de calibração (figuras 20 e 21), obtidas através do processo de simulação pelo programa FORGE 3 (2004). Porém a literatura 
mostra, que a presença de maiores teores de elementos de liga, afeta o coeficiente de atrito nos latões conforme Male (1966) mostrado na figura 9 ou em aços conforme Wang e Lenard (1992) mostrado na figura 10. Para estes autores, a presença de nióbio e vanádio, levou a coeficientes de atrito menor que para os demais aços. Este dado indica que um maior números de ensaios deve ser realizado para se avaliar quantitativamente o efeito da mudança de composição química dos aços.

O emprego de revestimento pareceu significativo, no coeficiente de atrito, conforme pode ser visto nas figuras 28 e 29. Porém, um estudo mais aprofundado do efeito dos revestimentos das matrizes deverá ser acompanhado do estudo simultâneo, dos efeitos da rugosidade nesta variável e da resistência ao desgaste, imposta pelo revestimento, uma vez que, como se sabe, a variação do coeficiente de atrito (ou não variação) não se relaciona com a resistência ao desgaste, citado por Sinatora (2005).

Apesar dos cuidados tomados, no decorrer do experimento, foi observada a formação de óxido (carepa) nas amostras, este fato pode ser visto nas figuras 30 e 31, onde é mostrada a mesma superfície de contato de duas amostras de anéis, com as matrizes.

Foram comparadas as amostras 26 e 27, que apresentaram coeficientes de atrito muito diferentes, a amostra 26 apresentou coeficiente de atrito 0,29 e a amostra 27 apresentou coeficiente de atrito 0,09 , conforme tabela 6 . A comparação, das duas superfícies foi feita através das fotografias das amostras, tiradas com ampliação de 4 vezes, conforme as figuras 30 e 31 . 


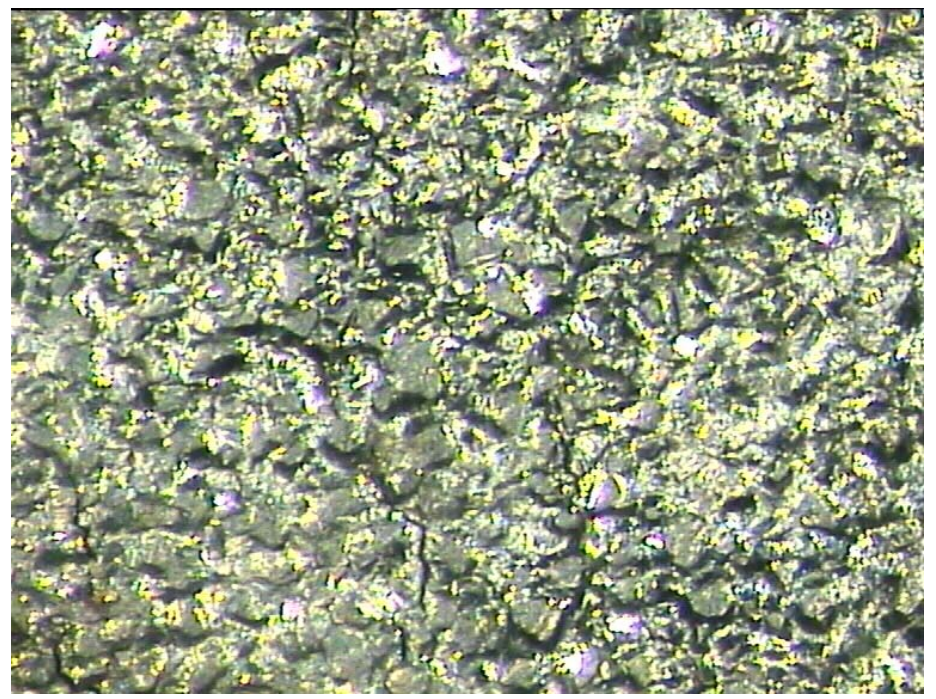

Figura 30: Superficie de contato da amostra 26 com a matriz, com ampliação de $4 x$

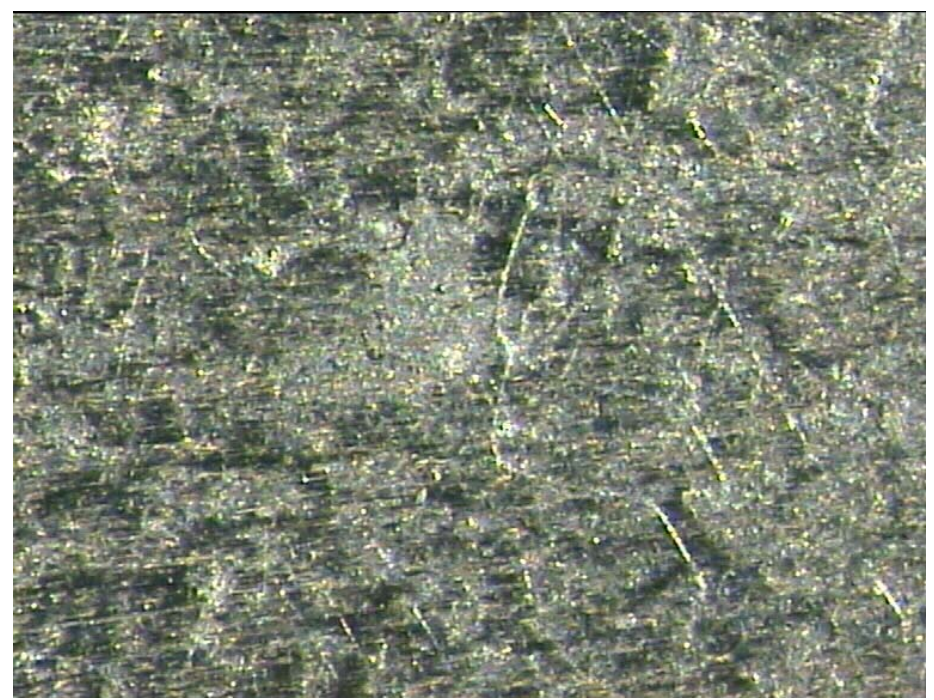

Figura 31: Superficie de contato da amostra 27 com a matriz,com ampliação de $4 x$

$\mathrm{Na}$ amostra 26, foi observada a maior formação de óxido. Aparentemente a maior formação de óxido favoreceu a determinação de coeficientes de atrito mais elevados. O papel dos óxidos nos valores de coeficiente de atrito durante a conformação plástica não está ainda suficientemente esclarecido como mostram os resultados contraditórios encontrados na literatura, conforme Cassarini, Villabon e Sinatora (2005). 
O aparecimento da superfície neutra, onde se tem a mudança do sentido de escoamento do material, foi descrito e equacionado no trabalho de Hawkyard e Johnson (1967). No presente trabalho, foi possível simular o aparecimento desta superfície como mostram as figuras 22 e 23 e empiricamente, mediante a observação de uma amostra seccionada (figura 32).

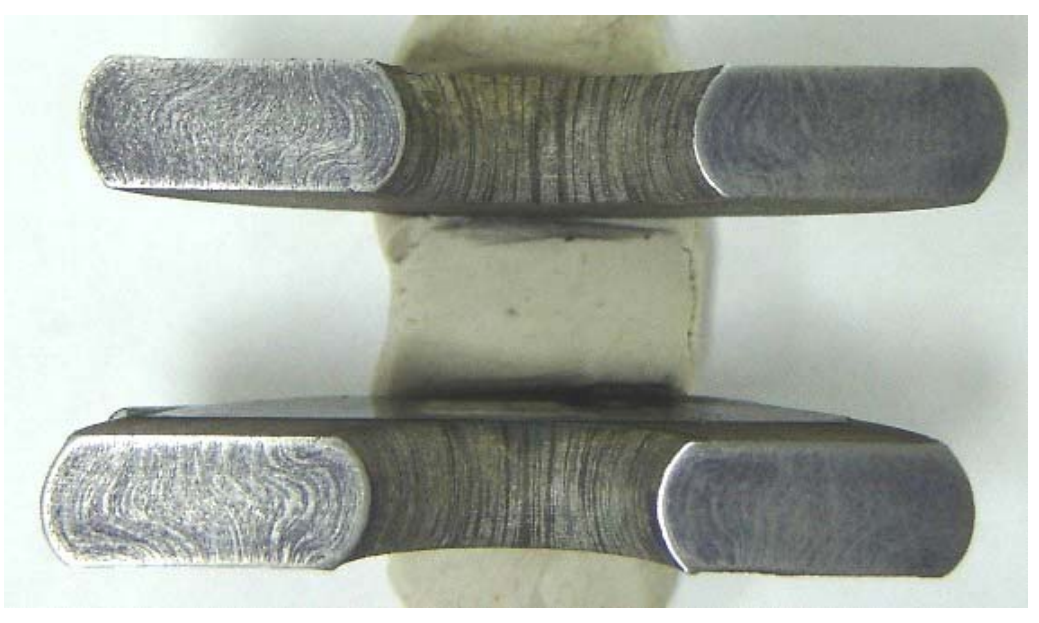

Figura 32: Corte da amostra 17 mostrando fibramento e a superficie neutra.

Através deste corte, foi possível fazer uma verificação do fibramento do material deformado e também a identificação da superfície neutra, que deverá se deslocar com a variação do atrito. Houve uma boa correspondência entre a evidência computacional e a evidência física. 


\section{CONCLUSÕES}

Durante a execução, das várias etapas deste experimento, muitos cuidados precisaram ser tomados, isto demonstra que o ensaio do anel necessita de conhecimentos aprofundados do processo de forjamento.

A representação analítica do ensaio mostra um grau de dificuldade significativo, que envolve muitos conceitos da conformação de metais, devendo sua análise ser criteriosamente interpretada.

A simulação do ensaio do anel, através do programa FORGE 3 (2004) e as curvas de calibração geradas a partir de seus resultados, apresentaram uma boa convergência com os resultados obtidos através dos experimentos, mostrando a coerência do modelo de atrito adotado e as demais considerações feitas para o experimento e para a simulação. Este processo permitiu uma boa estimativa da variação dos diâmetros internos dos anéis, bem como, do fluxo de material no interior dos mesmos e da superfície neutra.

A análise estatística dos resultados mostrou que a variável mais importante a interferir no coeficiente de atrito foi a temperatura, seguindo-se do tipo de revestimento das ferramentas, da velocidade e do material, porém, um maior número de ensaios e repetições devem ser feitos para obter-se uma análise quantitativa e para um estudo mais pormenorizado do efeito do material a ser forjado, do recobrimento das ferramentas e da rugosidade das mesmas no coeficiente de atrito.

A revisão da literatura, associada à realização dos experimentos, mostrou limitações no ensaio do anel. Em especial, nas limitações experimentais referentes ao controle da temperatura e ao controle da camada de óxido sobre os anéis. 


\section{REFERÊNCIAS BIBLIOGRÁFICAS}

ALTAN, T.; OH, S.; GEGEL, H. Conformação de metais fundamentos e aplicações. $1^{\text {a }}$ edição. São Paulo: EESC-USP, 1999.

AVITZUR, B. Friction during metal forming. In: BLAU, J., P. ASM Handbook. $2^{\mathrm{a}}$ edição, 1995. p 59-61

FORGING HANDBOOK. Introduction and applications. In: BYRER, T. G. Forging Handbook. Cleveland: Forging Industry Association, 1985. p. 1-24.

CASARINI, M.; VILLABÓN, L. R.; SINATORA, A. Determinação do coeficiente de atrito em altas temperaturas por meio de ensaio de deslizamento. In: CONGRESSO BRASILEIRO DE ENGENHARIA DE FABRICAÇÃO, $3^{\circ}$ COBEF., 2005, Joinville/SC, BR.

FORGING INDUSTRY ASSOCIATION: The forging industry vision Cleveland Ohio 1998. Disponível em: <http://www.forging.org/techno/Vision.htm>. Acesso em 21 mar. 2005.

HAWKYARD, J.B.; JOHNSON, W. An Analysis of the changes in geometry of a short hollow cylinder during axial compression. Int.J.Mech.Sci.Pergamon Press V. 9, p. 163-182, 1967.

HUTCHINGS, I.M. Tribology - friction and wear of engineering materials. London: Edward Arnold Publishers Ltd., 1992. 269p.

LANGE, K.; MEYER N.H. Gesenkschmieden 2a edição Berlin, Heidelberg, New York 1977 p. 1-5. 
MALE, A.T.; COCKROFT, M.G. A Method for determination of the coefficient of friction of metals under conditions of bulk plastic deformation. Journal of the Institute of Metals, V. 93, p. 38-46, 1964.

MALE, A.T. Variations in friction coefficients of metals during compressive deformation. Journal of the Institute of Metals, V. 94, p. 121-125, 1966.

MINITAB, Statistical software: conjunto de programas, 2000.

PETERSEN, S.B.; MARTINS, P.A.F.; BAY, N. Friction in bulk metal forming: A gerenal friction model vs.the law of constat friction. .Journal of Materials Processing Technology, V. 66, p. 186-194, 1997.

PETERSEN, S.B.; MARTINS, P.A.F.; BAY, N. An Alternative ring-test geometry for the evaluation of friction under low normal pressure. Journal of Materials Processing Technology, V. 79, p. 14-24, 1998.

SCHEY, A.; J. Tribology in metalworking: friction, lubrication and wear. Ohio: $2^{a}$ edição, 1984, p. 1-130.

SINATORA, A. Tribologia: Um resgate histórico e o estado da arte. (Erudição apresentada como parte dos requisitos do concurso para professor titular do departamento de Engenharia Mecânica) Escola Politécnica da Universidade de São Paulo, São Paulo, 2005.

TRANSVALOR FORGE 3 versão 6.3 Simulation software for material forming process: conjunto de programas 2004.

VETTER L. P. El uso del cobre arsenical en las culturas prehispanicas del norte del Peru, V. 41, Museo Del Ouro Bogotá, Colômbia, 1996, p. 63-80. 
WANG, F.; LENARD, J.G. An experimental study of interfacial friction-hot ring compression. Journal of Engineering Materials and Technology, Vol. 114, p. 13-18, 1992. 